\title{
A modeling framework for the integration of electrical and thermal energy systems in greenhouses
}

\author{
Queralt Altes-Buch $^{\mathrm{a}, *}$, Sylvain Quoilin ${ }^{\mathrm{a}}$, Vincent Lemort ${ }^{\mathrm{a}}$ \\ ${ }^{a}$ Energy Systems Research Unit, Faculty of Applied Sciences, University of Liège, Allée de \\ la Découverte 17, 4000 Liège, Belgium
}

\begin{abstract}
Greenhouse horticulture is associated to a significant energy consumption in temperate countries, mainly for lighting and for heating. Interestingly, the potential for energy optimization and energy savings is high but requires detailed models capable of considering various system configurations and control systems. This paper provides an open-source modeling framework capable of simulating and optimizing the design and the control of both the greenhouse and the generation systems covering all energy needs. The proposed model is composed of sub-models from different scientific fields: a greenhouse climate model, a crop yield model, a large number of energy generation and storage units models and different rule-based control strategies. The association of such state-of-the-art models in a single framework provides a powerful tool for optimization purposes and allows the definition of completely customized systems by means of an object-oriented interface. In this work, various control strategies are defined and simulated, thus demonstrating the capabilities of the proposed model. Results indicate that, by performing minor changes to the control of the thermal screen, heating consumption can be reduced by $3 \%$ without any loss in crop yield. The control of heat-generation units also has a significant impact on the operational costs, which vary by up to $17 \%$ when self-consumption levels are accounted for in the control strategy.
\end{abstract}

\footnotetext{
${ }^{*}$ Corresponding author

Email address: qaltes@uliege.be (Queralt Altes-Buch)
}

Preprint submitted to Elsevier

December 7, 2020 
Keywords: Greenhouse Climate Model, CHP, Greenhouse Climate Control, System Integration, Energy Management

\section{Introduction}

In the European context, the agriculture sector accounted for $2.7 \%$ of the EU-28 final energy consumption in 2016 [1]. A large share of this consumption originated from the greenhouse horticulture sector due to its high heating and electricity requirements. For instance, in a country like the Netherlands, greenhouses accounted for $79 \%$ of the total energy consumed by agriculture in 2013 , even though they represented only $0.5 \%$ of the total utilized agricultural area [2].

The improvement of energy efficiency in greenhouses has been the subject of a substantial literature. Over the past years, developments were primarily focused on energy saving solutions in order to decrease the energy requirements. However, energy supply in greenhouses still mostly relies on gas-fired units that inevitably contribute to $\mathrm{CO}_{2}$ emissions. In the context of the energy transition, it is important to identify how renewable energy sources (RES) can be utilized to supply the energy needs of greenhouses. Additionally, it is important to investigate the potential services that the remaining gas-fired units such as combined heat and power (CHP) can provide to the grid to facilitate the penetration of RES. Furthermore, as a multi-energy consumer requiring heating, electricity and $\mathrm{CO}_{2}$, greenhouses can provide good opportunities for flexibility across several energy sectors.

Applications of greenhouses integrated with low-carbon sources have been successfully implemented in many countries. For instance, in 2019, the Netherlands counted with 17 existing and 35 under-development geothermal projects to heat greenhouses $[3$. In parallel, the recovery of residual heat from industries is also being developed. An example is the under-construction heat network that uses the residual heat generated in the port of Rotterdam alone to heat a significant part of the 2385 -ha of greenhouses in Westland (and over 500000 
households) 4]. Although weather-dependent, applications with solar energy coupled to thermal energy storage (TES) are also being investigated and implemented. An example is the recent SOLHO off-grid unit [5], which serves $100 \%$ of the heating and electricity demand of a greenhouse in the South of France.

As previously mentioned, in order to help the integration of RES, the potential services provided by greenhouses to the grid should be investigated. CHP units in the horticulture sector have the ability to ramp-up to full capacity in less than one hour [6]. When coupled to TES, they can readily provide ancillary services or decentralised storage capacity for load balancing [7]. In a country such as the Netherlands, the CHP capacity dedicated to the agriculture and horticulture sectors was $3000 \mathrm{MW}_{e l}$ (for a national peak load of $18000 \mathrm{MW}_{e l}$ ) and represented $63.7 \%$ of the CHP installations in 2012 [8]. In 2016, these units accounted for $7.8 \%$ of the national electrical production $[9$.

A platform capable of simulating the greenhouse climate and the complex energy exchanges between greenhouses and their energy generation units is necessary to evaluate the potential contribution to the energy transition. A recent review listed 30 available models for greenhouse climate simulation [10. However, the existing models are incomplete in several aspects. First, although most of these models offer a small number of customized parameters, little flexibility is given on the greenhouse design. In fact, the models are calibrated for one type of greenhouse and do not allow selecting the modeled energy systems within the greenhouse. In addition, although the mathematical formulation of some of the models is openly presented (e.g. KASPRO), their implementation remains closed source. In a similar way, commercial climate simulation tools (e.g. CASTA, Hortinergy) are proprietary software that do not openly release code. Only recently a climate simulation model implemented in Matlab was released open-source [11, but does not include a user interface and has limited modularity. Finally, none of the reviewed existing models include the dynamic modeling of the energy supply and storage systems, which are required when evaluating the energy flexibility potential of greenhouses. This work aims at filling this gap by providing an open-source modeling framework capable of simulating and 
optimizing both the greenhouse climate and the energy systems. The framework offers a wide range of models that allow the configuration of completely customized systems by means of a user-friendly interface. The framework primarily consists in:

- A greenhouse climate model completely user-definable that was validated for a range of climates and greenhouse designs.

- A broad range of energy systems models, namely heating distribution (water-to-air and air-to-air), generation (CHP units, heat pumps, heating coils), storage, cooling (chiller, cooling coils), ventilation (natural and mechanical) and lighting (high pressure sodium).

- A crop yield model that accounts for the impact of indoor climate and hence energy saving solutions on productivity levels.

- A number of rule-based control strategies, both for the climate and the integrated system.

All the models parameters are user-definable. If no change is introduced by the user, typical values are assumed. The framework is written in the Modelica language and the proposed simulations are run within the Dymola software. The object-oriented nature of this language facilitates the simulation of completely customized systems. Users can build simulations by intuitively inter-connecting the available models in a 'physical' manner in the diagram interface [12. In addition, two models based on the Venlo-type greenhouse design are parametrized with typical values and are made available for simulation.

The developed modeling framework can be used for multiple purposes. For instance, to evaluate the potential of the aforementioned low-carbon energy sources (e.g. heat pumps, geothermal energy, heat recovery, solar energy etc.) as well as to define the optimal energy generation capacities in specific case studies. In addition, it can be used to optimally integrate the CHP or heat pump units with the electricity markets to provide flexibility. Finally, it can be used to analyze energy saving solutions for greenhouses as well as the sizing of their HVAC systems. Although the number of modeled energy systems remains limited, the 
full compatibility (connector-wise) of the framework allows the connection to other Modelica libraries (e.g. Buildings [13], IDEAS [14, ThermoCycle [15], ThermoPower [16, etc.). These include a wide range of models such as district heating networks, solar cycles, dwellings or other HVAC systems. The modeling framework was successfully used in a previous work [17 to simulate an urban agricultural site. The obtained results showed that a district heating network connecting a residential building stock can increase its efficiency by adding a greenhouse to the network. In 2019, the modeling framework was also used in the Autonomous Greenhouses International Challenge [18 to train an artificial intelligence (AI) algorithm controlling a greenhouse remotely, which opens an interesting and yet unexplored field of research.

This paper is organized as follows. Section 2 elaborates on state-of-the-art greenhouse climate simulation models and provides the theoretical background used for the developed framework. Section 3 describes the case study and introduces the six simulated control strategies. Section 4 discusses the obtained results, thus demonstrating the capabilities of the proposed modeling framework. Finally, Section 5 concludes with the main findings and provides recommendations for future research.

\section{Methods}

\subsection{Greenhouse climate model}

Most of the reported greenhouse climate models in the literature (e.g. [19, 20, 21, 22, 23]) are defined for a specific location and for a specific greenhouse structure and outdoor climate. In this work, a more generic greenhouse climate model [24] combining, among others, the work of [19] and 20] has been implemented. The heat transfer model has however been improved with respect to these models, in which an isothermal hypothesis is used for the heat transfer from the heating pipes. A more detailed approach in which the water flowing through the pipes is modeled by means of a discretized model that divides the pipes into several cells is preferred for the sake of model accuracy. 


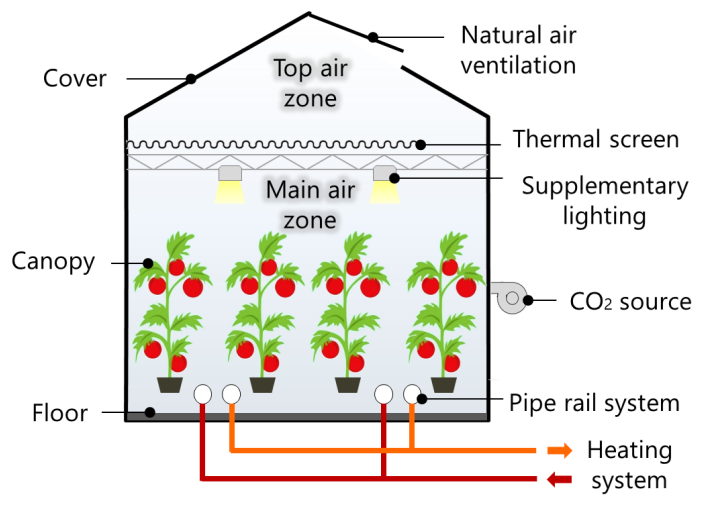

Figure 1: Example of a greenhouse and its components

The greenhouse climate model describes the indoor climate of a greenhouse resulting from a greenhouse design, outdoor climate and a specific control. In greenhouses, the indoor climate is characterized by the temperature, the humidity and the $\mathrm{CO}_{2}$ concentration in the air. The climate is influenced by all the elements in the greenhouse and the energy flows between them. These elements, shown in Figure 1, are mainly the air, the canopy, the envelope (i.e. the cover and the floor), the heating pipes and the thermal screen. For instance, the canopy temperature has an impact on its photosynthesis and transpiration, which decrease the $\mathrm{CO}_{2}$ concentration and increase the moisture content of the air. The temperature of the envelope influences the vapor pressure of water of the air, which is decreased by condensation at the cover and at the thermal screen. The thermal screen is an horizontally movable membrane used to reduce the far-infrared radiative losses to the cover and to the sky. When the screen is deployed, the air of the greenhouse is divided in two zones, i.e. below and above the screen. These zones, entitled main and top zones, are modeled separately and their respective climate is assumed to be homogeneous.

The description of the implemented greenhouse climate model is organized as follows. Subsections 2.1.1, 2.1.2 and 2.1.3 respectively describe the sensible energy, moisture and $\mathrm{CO}_{2}$ balances in the climate model. Subsections 2.1.4. 2.1.5 and 2.1.6 respectively describe the energy, moisture and $\mathrm{CO}_{2}$ flows between 


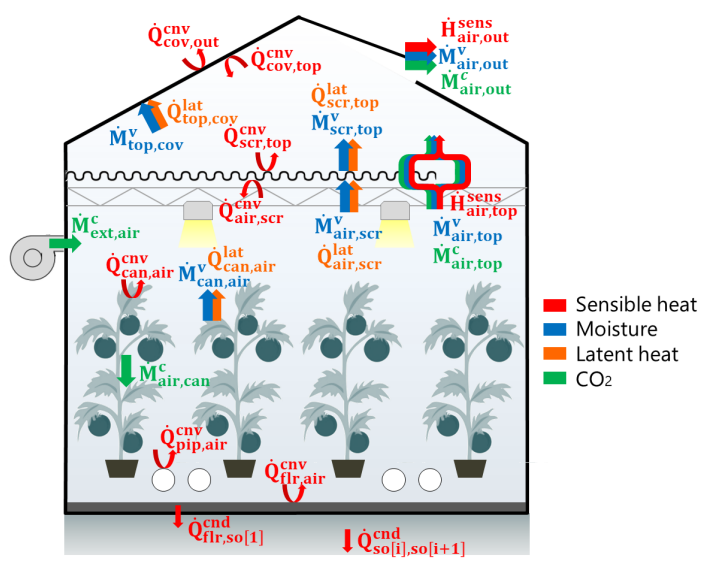

Figure 2: Schematic representation of the greenhouse climate model flows related to sensible heat, moisture transfer, latent heat and $\mathrm{CO}_{2}$ transfer

the greenhouse components.

\subsubsection{Sensible energy balance}

The first state variable describing the greenhouse climate is the dry-bulb air temperature. This temperature is computed by applying a sensible energy balance on each component. The general form of this balance is defined by equation (1):

$$
\rho c_{p} V \frac{d T}{d t}=\sum \dot{Q}+\sum \dot{H}^{\text {sens }}
$$

where $\dot{Q}$ includes the convection $\left(\dot{Q}^{c n v}\right)$ and conduction flows $\left(\dot{Q}^{c n d}\right)$, and $\dot{H}^{\text {sens }}$ includes the sensible heat related to a mass transfer. When equation (1) applies to a surface, $\dot{H}^{\text {sens }}$ is null and $\dot{Q}$ also includes the long-wave radiation flows $\left(\dot{Q}^{r a d}\right)$, the absorption of short-wave radiation $\left(\dot{Q}^{s w r}\right)$ and the latent heat flows from evaporation or condensation $\left(\dot{Q}^{l a t}\right)$. These flows are graphically represented in Figures 2 and 3 .

The energy balance on the main air zone is described by equation (2). The temperature of the air is increased primarily by the heating system, but also by the short-wave radiation absorbed by the greenhouse components and later exchanged through convection to the air. Additionally, because of the screen material porosity, sensible energy and moisture are exchanged between both 


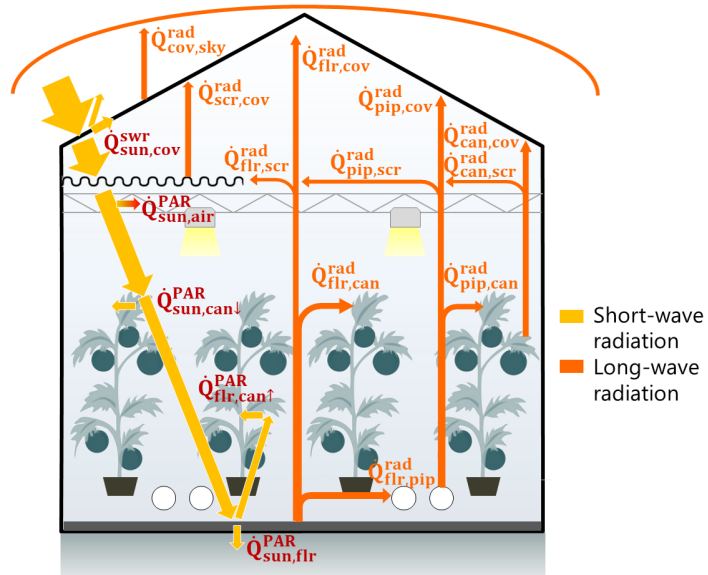

Figure 3: Schematic representation of the greenhouse climate model flows related to long-wave radiation and the absorption of short-wave photosynthetically active radiation (PAR)

zones. The air is further cooled down by natural ventilation through the vents as well as by infiltrations or exfiltrations through the greenhouse envelope.

$$
\begin{aligned}
\rho_{a i r} c_{p, a i r} V_{a i r} \frac{d T_{a i r}}{d t} & =\dot{Q}_{s u n, a i r}^{s w r}+\dot{Q}_{i l u, a i r}^{s w r}+\dot{Q}_{p i p, a i r}^{c n v} \\
& +\dot{Q}_{c a n, a i r}^{c n v}-\dot{Q}_{a i r, f l r}^{c n v}-\dot{Q}_{a i r, c o v}^{c n v} \\
& -\dot{Q}_{a i r, s c r}^{c n v}-\dot{H}_{a i r, t o p}^{s e n s}-\dot{H}_{a i r, \text { out }}^{s e n s}
\end{aligned}
$$

The energy balance on the cover is described by equation (3). The temperature of the cover depends on the convective heat flows with the indoor and outdoor air. Depending on the water vapor pressure difference with respect to the air, condensation at the inner side of the cover may occur. The convective and latent flows are modeled between the cover and the main air zone if the greenhouse has no thermal screen or in case the screen is open. However, when the screen is deployed, they are included in the energy balance of the top air zone. Long-wave radiation is modeled between the cover and all the greenhouse components, as well as the sky. The model also includes the absorbed incident 
solar radiation. Therefore, the energy balance on the cover is described by:

$$
\begin{aligned}
\rho_{c o v} c_{c o v} & V_{c o v} \frac{d T_{c o v}}{d t}=\dot{Q}_{s u n, c o v}^{s w r}+\dot{Q}_{t o p, c o v}^{c n v}+\dot{Q}_{t o p, c o v}^{l a t} \\
& +\dot{Q}_{a i r, c o v}^{c n v}+\dot{Q}_{a i r, c o v}^{l a t}+\dot{Q}_{p i p, c o v}^{r a d}+\dot{Q}_{c a n, c o v}^{r a d} \\
& +\dot{Q}_{f l r, c o v}^{r a d}+\dot{Q}_{s c r, c o v}^{r a d}-\dot{Q}_{c o v, \text { out }}^{c n v}-\dot{Q}_{c o v, s k y}^{r a d}
\end{aligned}
$$

The energy balance on the canopy is defined by equation (4), where the heat capacity per unit of leaf area is a constant estimated by [25]. The magnitude of the energy exchanged by the canopy depends on the size of its leaves, which is increased by crop growth and decreased by leaf pruning. The leaf area index (LAI), defined as the leaf area per unit of ground area, is a variable used to quantify this. The short-wave radiation absorbed by the canopy depends on its absorption coefficients, which differ according to the spectrum of the incident radiation.

$$
\begin{array}{r}
c_{l e a f} L A I \frac{d T_{c a n}}{d t}=\dot{Q}_{s u n, c a n}^{s w r} \\
+\dot{Q}_{i l u, c a n}^{s w r}+\dot{Q}_{p i p, c a n}^{r a d} \\
-\dot{Q}_{c a n, a i r}^{c n v}-\dot{Q}_{c a n, a i r}^{l a t}-\dot{Q}_{c a n, c o v}^{r a d} \\
-\dot{Q}_{c a n, f l r}^{r a d}-\dot{Q}_{c a n, s c r}^{r a d}
\end{array}
$$

The energy balance on the floor is defined by equation (5). The floor temperature is increased by the absorbed short-wave radiation from the sun and from supplementary lighting. Moreover, it is influenced by long-wave radiation flows, convection with the air and conduction through the ground.

$$
\begin{array}{r}
\rho_{f l r} c_{f l r} V_{f l r} \frac{d T_{f l r}}{d t}=\dot{Q}_{s u n, f l r}^{s w r}+\dot{Q}_{i l u, f l r}^{s w r}+\dot{Q}_{p i p, f l r}^{r a d} \\
+\dot{Q}_{c a n, f l r}^{r a d}+\dot{Q}_{a i r, f l r}^{c n v}-\dot{Q}_{f l r, c o v}^{c n v} \\
-\dot{Q}_{f l r, s c r}^{c n v}-\dot{Q}_{f l r, s o[1]}^{c l d}
\end{array}
$$

To account for the high thermal capacity of the floor, conduction through the ground is modeled by means of a nodal model. The ground is divided into several layers, whose thickness increases with the depth. The temperature of the ground layer ' $i$ ' is described by the energy balance of equation (6). The temperature of the deepest layer is a boundary condition. The model is written 
in a general form so that the ground can be made of a single material (e.g. soil) or a combination of materials (e.g. concrete layers on top of soil).

$$
\rho_{s o[i]} c_{s o[i]} V_{s o[i]} \frac{d T_{s o[i]}}{d t}=\dot{Q}_{s o[i-1] s o[i]}^{c n d}-\dot{Q}_{s o[i] s o[i+1]}^{c n d}
$$

The energy balance on the screen is described by equation (7). Although the radiative, convective and latent heat flows are modeled for both sides of the screen, the latter is assumed to be at a single temperature. This assumption is justified by the fact that its thickness (commonly lower than $1 \mathrm{~mm}$ ) implies a very low heat capacity. Since the screen is mostly deployed at night (i.e. when there is no sunlight), the absorbed heat from short-wave radiation is neglected. It should be noted that the flows related to the screen are function of the screen position, i.e. they are null if the screen is completely open.

$$
\begin{aligned}
\rho_{s c r} c_{s c r} & V_{s c r} \frac{d T_{s c r}}{d t}=\dot{Q}_{p i p, s c r}^{r a d}+\dot{Q}_{c a n, s c r}^{r a d} \\
+ & \dot{Q}_{f l r, s c r}^{r a d}+\dot{Q}_{a i r, s c r}^{c n v}+\dot{Q}_{a i r, s c r}^{l a t} \\
- & \dot{Q}_{s c r, t o p}^{c n v}-\dot{Q}_{s c r, t o p}^{l a t}-\dot{Q}_{s c r, c o v}^{r a d}
\end{aligned}
$$

As previously stated, when the screen is deployed, the indoor air is divided in two zones. In that case, the model computes an energy balance in each air zone. Thus, the flows that take place above the screen are no longer considered in equation (2) but in the top air balance. This energy balance is described by equation (8).

$$
\begin{aligned}
\rho_{\text {top }} c_{p, t o p} V_{\text {top }} \frac{d T_{t o p}}{d t} & =\dot{Q}_{s c r, t o p}^{c n v}+\dot{H}_{\text {air }, \text { top }}^{\text {sens }} \\
& -\dot{Q}_{t o p, \text { cov }}^{c n v}-\dot{H}_{\text {top }, \text { out }}^{\text {sens }}
\end{aligned}
$$

\subsubsection{Moisture balance}

The second characteristic describing the greenhouse climate is the moisture content of the air, which is increased by the transpiration of the canopy and decreased by the ventilation and by the condensation on the cover and on the screen. In the model, the main state variable is the water vapor pressure of the air, which is computed by applying a moisture mass balance on the main and 
top air zones (equations $(9)$ and $(10)$, respectively).

$$
\begin{aligned}
& M_{v} \frac{V_{a i r}}{R T} \frac{d P_{a i r}^{v}}{d t}=\dot{M}_{c a n, a i r}^{v}-\dot{M}_{a i r, c o v}^{v}-\dot{M}_{a i r, s c r}^{v} \\
& -\dot{M}_{a i r, t o p}^{v}-\dot{M}_{a i r, \text { out }}^{v} \\
& M_{v} \frac{V_{t o p}}{R T} \frac{d P_{t o p}^{v}}{d t}=\dot{M}_{a i r, t o p}^{v}+\dot{M}_{s c r, t o p}^{v} \\
& -\dot{M}_{t o p, c o v}^{v}-\dot{M}_{t o p, o u t}^{v}
\end{aligned}
$$

To compute the flows related to condensation and evaporation, the water vapor pressure of the surfaces (i.e. the canopy, the cover and the screen) is defined as the saturated vapor pressure at the surface temperature. As suggested by [20, the mass transfer capacity of the air is assumed to be independent of its temperature (i.e. $T=291 \mathrm{~K}$ in equation (9) and (10)).

\subsection{3. $\mathrm{CO}_{2}$ balance}

The third state variable describing the greenhouse climate is the $\mathrm{CO}_{2}$ mass concentration of the air, which is determined by means of a $\mathrm{CO}_{2}$ mass balance. The $\mathrm{CO}_{2}$ concentration of the indoor air is decreased by ventilation and the $\mathrm{CO}_{2}$ consumption of the canopy. At the same time, it can be increased by the $\mathrm{CO}_{2}$ supply from an external source. The $\mathrm{CO}_{2}$ mass concentration of the main and top air zones is described by equations (11) and (12), respectively.

$$
\begin{gathered}
V_{a i r} \frac{d \gamma_{a i r}^{c}}{d t}=\dot{M}_{e x t, a i r}^{c}-\dot{M}_{a i r, c a n}^{c}-\dot{M}_{a i r, t o p}^{c}-\dot{M}_{a i r, o u t}^{c} \\
V_{t o p} \frac{d \gamma_{t o p}^{c}}{d t}=\dot{M}_{a i r, t o p}^{c}-\dot{M}_{t o p, o u t}^{c}
\end{gathered}
$$

\subsubsection{Sensible energy flows}

Since all the components are uniformly distributed, all model flows (energy, moisture, $\mathrm{CO}_{2}$ ) are described per square meter of greenhouse floor.

Convection. The convective heat flow on a surface is function of the heat exchange coefficient $\left(U_{i j}\right)$ and is described by:

$$
\dot{q}_{i j}^{c n v}=U_{i j}\left(T_{i}-T_{j}\right)
$$


The calculation method for the heat exchange coefficient depends on the type of convection. Most of the convective processes in greenhouses are governed by free convection. Nonetheless, some are considered to be forced. In free convection, the Nusselt number $(\mathrm{Nu})$ describing the convective exchange can be defined as a function of the Rayleigh number (Ra) [26]. By means of the $\mathrm{Nu}$-Ra relation, 20] described the heat exchange coefficients for free convection processes. In forced convection, the heat exchange coefficients are derived from experimental results. This is the case of the outer side of the greenhouse cover, where convection is driven by wind speed. The heat exchange on the heating pipes can also be considered to be hindered if the pipes are situated close to the floor and are surrounded by leaves. Therefore, their heat transfer coefficient is modeled differently than for pipes in free air. These two forced convection processes were fitted by [19] using experimental data. All the heat transfer coefficients are presented in Table 1 .

Conduction. The only conductive flow considered in greenhouse modeling is the conduction through the soil. The ground under the greenhouse floor represents a significant thermal capacity with a poor thermal conductivity. In order to describe the temperature gradient, the soil is modeled in several layers. The heat flow between the layers is described by equation (13), using the conduction heat exchange coefficient from Table 1.

Ventilation. In the greenhouse, air exchange is mainly driven by natural ventilation between the indoors and outdoors as well as between the main and top air zones. Their convective flows are modeled by an air exchange rate between two volumes $i$ and $j$, as described by:

$$
\dot{h}_{i j}^{\text {sens }}=\rho_{\text {air }} c_{p, a i r} \dot{v}_{i j}\left(T_{i}-T_{j}\right)
$$

As shown in Figure 2, the ventilation flow between the main and top air zones is a combination of two air flows: i) through the screen fabric pores and ii) through a gap when the screen is not fully deployed. The former was derived from experimental data obtained by studying the temperature-driven flow 
Table 1: Heat exchange coefficients for convective and conductive heat transfer

\begin{tabular}{|c|}
\hline Heat exchange coefficients $U_{i j}\left[\mathrm{~W} \mathrm{~m}^{-2} \mathrm{~K}^{-1}\right]$ \\
\hline Free convection \\
\hline$U_{\text {can }, a i r}=2 \cdot L A I \cdot U_{\text {leaf,air }}$ \\
\hline$U_{a i r, f l r}= \begin{cases}1.7\left(T_{f l r}-T_{a i r}\right)^{0.33}, & \text { if } T_{f l r}>T_{a i r} \\
1.3\left(T_{a i r}-T_{f l r}\right)^{0.25}, & \text { otherwise }\end{cases}$ \\
\hline$U_{\text {air }, \text { scr }}=u_{\text {scr }} 1.7\left|T_{a i r}-T_{s c r}\right|^{0.33}$ \\
\hline$U_{s c r, t o p}=u_{s c r} 1.7\left|T_{s c r}-T_{t o p}\right|^{0.33}$ \\
\hline$U_{\text {air }, \text { cov }}=\left(1-u_{s c r}\right) 1.7\left(T_{\text {air }}-T_{\text {cov }}\right)^{0.33} \cos \varphi^{-0.66}$ \\
\hline$U_{t o p, c o v}=u_{s c r} 1.7\left(T_{a i r}-T_{c o v}\right)^{0.33} \cos \varphi^{-0.66}$ \\
\hline$U_{\text {pip,air }}=1.28 \pi d_{\text {pip }}^{0.75} l_{\text {pip }}\left|T_{\text {pip }}-T_{a i r}\right|^{0.25}$ \\
\hline
\end{tabular}

Hindered convection

$U_{\text {pip }, \text { air }}=1.99 \pi d_{\text {pip }} l_{\text {pip }}\left|T_{\text {pip }}-T_{\text {air }}\right|^{0.32}$

Forced convection

$U_{\text {cov }, \text { out }}= \begin{cases}\left(2.8+1.2 v_{w}\right) \frac{1}{\cos \varphi}, & \text { if } v_{w}<4\left[\mathrm{~m} \mathrm{~s}^{-1}\right] \\ 2.5 v_{w}^{0.8} \frac{1}{\cos \varphi}, & \text { otherwise }\end{cases}$

Conduction

$U_{s o[i-1] s o[i]}=\frac{2}{\frac{e_{s o[i-1]}}{\lambda_{s o[i-1]}}+\frac{e_{s o[i]}}{\lambda_{s o[i]}}}$ 
through fully deployed screens $\left(u_{s c r}=1\right)[26$. The latter, which dominates the exchange, was theoretically modeled by [27] using the Navier-Stokes equation. Combining both air flow rates, the total ventilation rate between the main and top zones is described by:

$$
\begin{array}{r}
\dot{v}_{\text {air }, \text { top }}=u_{s c r} K_{\text {scr }}\left|T_{\text {air }}-T_{\text {top }}\right|^{0.66} \\
+\frac{1-u_{s c r}}{\bar{\rho}} \sqrt{0.5 \bar{\rho} W g\left(1-u_{s c r}\right)\left|\rho_{\text {air }}-\rho_{\text {top }}\right|}
\end{array}
$$

where $\bar{\rho}$ is the mean value between the main and top air zones density.

The air flow rate to the outside air through the roof windows mainly depends on the windows opening $\left(u_{v e n}\right)$, but also on the wind pressure coefficient and the coefficient of energy discharge caused by friction at the windows [28]:

$$
\dot{v}_{a i r, \text { out }}=\frac{u_{\text {ven }} A_{\text {ven }} K_{d}}{2 A_{\text {flr }}} \sqrt{g \frac{h_{\text {ven }}}{2} \frac{T_{a i r}-T_{\text {out }}}{\bar{T}}+K_{w} v_{w}^{2}}
$$

The total ventilation rate of the greenhouse is influenced by the leakage rate through the greenhouse structure, which is linearly dependent on wind speed and is a function of the leakage coefficient of the greenhouse. The latter has a constant value, characteristic of the structure. The leakage rate is described by:

$$
\dot{v}_{\text {leak }}= \begin{cases}0.25 K_{\text {leak }}, & \text { if } v_{w}<0.25 \\ v_{w} K_{\text {leak }}, & \text { otherwise }\end{cases}
$$

Long-wave radiation. Long-wave radiation is modeled between all greenhouse components and between the cover and the sky. The Stefan-Boltzmann equation is written:

$$
\dot{q}_{i j}^{r a d}=A_{i} \varepsilon_{i} \varepsilon_{j} F_{i j} \sigma\left(T_{i}^{4}-T_{j}^{4}\right)
$$

The emission coefficients are characteristic of the surfaces and the view factors of the greenhouse elements are described in [20].

Latent heat flows. The latent heat from condensation or evaporation flows is function of the moisture mass flow rate associated to its process, as described by:

$$
\dot{q}_{i j}^{l a t}=\Delta h_{f g} \dot{m}_{i j}^{v}
$$


where the heat of vaporization of water $\left(\Delta h_{f g}\right)$ is computed at $21^{\circ} \mathrm{C}$.

Short-wave radiation. Short-wave radiation in a greenhouse originates from the sun or from supplementary lighting. Although the contribution of supplementary lighting is small during summer, in winter it can double the solar input through a day and thus, have an important impact on crop growth. The solar radiation incident on a greenhouse can be split in three spectral parts: ultra violet (UV, from 0.3 to $0.4 \mu \mathrm{m}$ ), visible light (from 0.4 to $0.7 \mu \mathrm{m}$ ) and near infrared light (NIR, from 0.7 to $3 \mu \mathrm{m}$ ). The visible light has an interest for biological growth and is referred as photosynthetically active radiation (PAR). The portion of UV and PAR of the global radiation is $6-10 \%$ and $45-60 \%$, respectively [29]. However, for plant growth it is common to assign $50 \%$ to PAR $\left(\eta^{P A R}\right)$, neglect the UV and assign the other $50 \%$ to NIR $\left(\eta^{N I R}\right)$ [20. As proposed by [24, the solar model of this work is simplified by making no distinction between diffuse and direct solar radiation and by assuming that the transmission coefficient of the greenhouse cover does not depend on the solar angle.

The heat flow from the solar radiation absorbed by the cover is described by:

$$
\dot{q}_{\text {sun }, \text { cov }}^{\text {swr }}=\alpha_{\text {cov }} I^{G}
$$

The radiation that is not reflected or absorbed by the cover is transmitted into the greenhouse. Since the absorption coefficients of the canopy and floor differ according to the spectrum, their absorbed heat flow is computed separately for PAR and NIR. The transmitted PAR, i.e. the PAR above the canopy, can be defined by:

$$
I_{\tau}^{P A R}=\left(1-\eta_{\text {air }}^{G}\right) \tau_{\text {cov }}^{P A R} \eta^{P A R} I^{G}
$$

where $\eta_{\text {air }}^{G}$ is the ratio of the radiation that is absorbed by the greenhouse elements and is later released to the air.

The deployment of the thermal screen may reduce the amount of transmitted light. Thus, $\tau_{\text {cov }}^{P A R}$ is a lumped value of the greenhouse cover and the movable thermal screen transmission coefficients. 
Part of the transmitted radiation is absorbed by the canopy and the floor. As shown in Figure 3 , the PAR absorbed by the canopy is a combination of the PAR directly absorbed by the canopy and the PAR reflected by the greenhouse floor and then absorbed by the canopy:

$$
\dot{q}_{\text {sun }, \text { can }}^{P A R}=\dot{q}_{\text {sun }, \text { can } \downarrow}^{P A R}+\dot{q}_{f l r, c a n \uparrow}^{P A R}
$$

In a homogeneous crop, the absorbed radiation is described by an exponential decomposition of light with the LAI [30]:

$$
\begin{gathered}
\dot{q}_{\text {sun }, \text { can } \downarrow}^{P A R}=I_{\tau}^{P A R}\left(1-\rho_{\text {can }}^{P A R}\right)\left(1-e^{-L A I \cdot K^{P A R}}\right) \\
\dot{q}_{f l r, c a n \uparrow}^{P A R}=I_{\tau}^{P A R} e^{-L A I \cdot K^{P A R}} \rho_{f l r}^{P A R}\left(1-\rho_{\text {can }}^{P A R}\right)\left(1-e^{-L A I \cdot K^{P A R}}\right)
\end{gathered}
$$

The heat flow of PAR absorbed by the floor is described by:

$$
\dot{q}_{\text {sun } f l r}^{P A R}=I_{\tau}^{P A R}\left(1-\rho_{f l r}^{P A R}\right)\left(1-e^{-L A I \cdot K^{P A R}}\right)
$$

Since the PAR reflection coefficient of the canopy and floor is low, the restant PAR reflected back into the greenhouse is neglected. On the contrary, a nonnegligible share of NIR is reflected by the canopy and floor. This share, which is again scattered, increases the NIR absorbed by the canopy and the floor. In the model, the absorbtions are lumped into a single coefficient $\left(\alpha_{c a n}^{N I R}\right.$ and $\left.\alpha_{f l r}^{N I R}\right)$, which is computed as proposed by [24]. The absorbed heat flow from NIR for the canopy and floor are described by:

$$
\begin{aligned}
& \dot{q}_{\text {sun }, \text { can }}^{N I R}=\alpha_{c a n}^{N I R}\left(1-\eta_{\text {air }}^{G}\right) \eta^{N I R} I^{G} \\
& \dot{q}_{\text {sun }, \text { flr }}^{N I R}=\alpha_{f l r}^{N I R}\left(1-\eta_{\text {air }}^{G}\right) \eta^{N I R} I^{G}
\end{aligned}
$$

Part of transmitted radiation not absorbed by the canopy or the floor is assumed to be absorbed by the greenhouse structural elements and later released to the greenhouse air. This heat flow is described by:

$$
\dot{q}_{\text {sun }, \text { air }}^{s w r}=\eta_{\text {air }}^{G} I^{G}\left(\tau_{\text {cov }}^{P A R} \eta^{P A R}+\left(\alpha_{c a n}^{N I R}+\alpha_{f l r}^{N I R}\right) \eta^{N I R}\right)
$$

The heat absorption flows from the short-wave radiation coming from supplementary lighting are computed in a similar manner. For PAR, they are 
computed with equations 22 - 25 by replacing $I_{\tau}^{P A R}$ by the PAR emitted by supplementary lighting. For NIR, they are computed with equations (26)-(27), with recalculated absorption coefficients. It should be noted that only part of the electric consumption of the supplementary lighting is converted to short-wave radiation. In addition, the fraction of PAR and NIR of the emitted radiation depends on the type of lighting. For instance, high intensity discharge lamps e.g. high pressure sodium (HPS) lamps convert $17 \%$ of the electrical power to NIR and $25 \%$ to PAR [31]. The remaining $58 \%$ is released to the greenhouse air in the form of heat.

\subsubsection{Moisture flows}

Condensation and evaporation. Condensation on a surface is governed by processes at the boundary layer of the surface, whose moisture transport mechanism is similar to the one of heat transfer. This similarity implies a correlation between the heat and moisture transfer coefficients. For instance, the moisture exchange coefficient for condensation or evaporation is linearly related to the convective heat exchange coefficient on that surface [20]. The moisture flow of condensation or evaporation on a surface is described by:

$$
\dot{m}_{i j}^{v}= \begin{cases}\xi U_{i j}\left(P_{i}^{v}-P_{j}^{v}\right), & \text { if } P_{i}^{v}>P_{j}^{v} \\ 0, & \text { otherwise }\end{cases}
$$

where $\xi=6.4 \cdot 10^{-9}$ and $U_{i j}$ is obtained from Table 1 , $i$ and $j$ correspond to the air and the surface for condensation, and vice versa for evaporation.

Condensation is modeled on the inner side of the cover and the lower side of the screen. As previously stated, air and moisture are exchanged through the screen fabric. The model assumes that the screen is capable of transporting water from its lower side to its upper side. Storage of water in the screen is neglected. Therefore, evaporation from the upper side is only possible when condensation takes place at the lower side. This implies that the rate of evaporation is lower or equal to the rate of condensation. In other words, the model assumes that the condensate is either evaporated at the upper side of the screen 
or dripped from the screen. To take this into account, the evaporation mass flow rate is computed with a modified version of equation 29$)$ :

$$
\dot{m}_{i j}^{v}=\left\{\begin{array}{c}
\min \left(\xi U_{i j}, \xi U_{a i r, i} \frac{P_{a i r}^{v}-P_{i}^{v}}{P_{i}^{v}-P_{j}^{v}}\right)\left(P_{i}^{v}-P_{j}^{v}\right), \\
\quad \text { if } P_{i}^{v}>P_{j}^{v} \\
0, \quad \text { otherwise }
\end{array}\right.
$$

where $i$ and $j$ correspond to the screen and the top air zone, respectively.

Ventilation. The moisture flow exchanged in a ventilation process (i.e. maintop, indoor-outdoor) is related to its air flow rate (equations $15-(16)$ ) and is described by:

$$
\dot{m}_{i j}^{v}=\frac{M_{H 2 O} \dot{v}_{i j}}{R}\left(\frac{P_{i}^{v}}{T_{i}}-\frac{P_{j}^{v}}{T_{j}}\right)
$$

Canopy transpiration. The transpiration flow from the canopy originates from a phase interface somewhere inside the cavities of a leaf. The resistance to vapor transport from the canopy leaves to the greenhouse air is made of an internal resistance $\left(r_{s}\right)$ and a boundary layer resistance $\left(r_{b}\right)$ 25]. The internal resistance, and hence the canopy transpiration, is function of the short-wave radiation, the temperature, the $\mathrm{CO}_{2}$ concentration and the water vapor pressure in the air. The canopy transpiration can be defined as:

$$
\dot{m}_{c a n, a i r}^{v}=\frac{2 \rho_{a i r} c_{p, a i r} L A I}{\Delta h_{f g} \gamma\left(r_{b}+r_{s}\right)}\left(P_{c a n}^{v}-P_{a i r}^{v}\right)
$$

\subsection{6. $\mathrm{CO}_{2}$ flows}

Ventilation. Similar to moisture transfer, the $\mathrm{CO}_{2}$ flow accompanying a natural ventilation flow is function of its air flow rate (equations (15)-16) and is described by:

$$
\dot{m}_{i j}^{c}=\dot{v}_{i j}\left(\gamma_{i}^{c}-\gamma_{j}^{c}\right)
$$

Photosynthesis. The $\mathrm{CO}_{2}$ flow absorbed by the canopy depends on its photosynthesis rate and respiration processes. It is computed in the crop yield model in the next section. 


\subsection{Crop yield model}

Several inputs used in the computation of the greenhouse climate (e.g. the LAI, the $\mathrm{CO}_{2}$ flow absorbed by the canopy) are characteristics of the crop and must be quantified by a dynamic crop growth model. In addition, crop growth models allow to compare the yield and hence, the profitability (e.g. savings in energy) from different control strategies. For those reasons, a dynamic crop yield model is implemented.

Crop growth is related to the carbohydrate intake by the fruits, leaves and stems. The crop's carbohydrate input, which comes from photosynthesis, passes through a buffer before being distributed. As every storage system, the buffer has a maximum capacity above which no inflow (i.e. photosynthesis) is possible, and a lower limit below which no outflow (i.e. distribution) is allowed. The inand out-flows depend on the state of charge of the buffer and thereby, may not be simultaneous. For instance, although the photosynthesis flow is only positive during daylight, the carbohydrates distribution may continue at nighttime if the state of charge allows it.

Models for tomato crops accounting for the dynamics of the carbohydrate buffer are available in the current literature (e.g. 32, 33, 34, 35, 36). In this work, a relatively recent yield model developed and validated for a variety of temperatures [37] is implemented. The model structure is shown in Figure 4 Given that yield models differ between crops, the model implemented in this work is only valid for tomato crop, but can easily be adapted for other varieties.

The availability of carbohydrates in the buffer is described by a mass balance that takes into account the inflow from photosynthesis, the outflow to the leaves, the fruits and the stems (and roots), and the growth respiration of the plant:

$$
\begin{aligned}
\frac{d m_{b u f}^{c h}}{d t}=\dot{m}_{a i r, b u f}^{c h} & -\dot{m}_{b u f, f r u}^{c h}-\dot{m}_{b u f, l e a f}^{c h} \\
& -\dot{m}_{b u f, \text { stem }}^{c h}-\dot{m}_{b u f, \text { air }}^{c h}
\end{aligned}
$$

The photosynthesis flow is function of the canopy temperature, the $\mathrm{CO}_{2}$ concentration of the greenhouse air and the PAR absorbed by the canopy. Their values are retrieved from the greenhouse climate simulation model, in which 


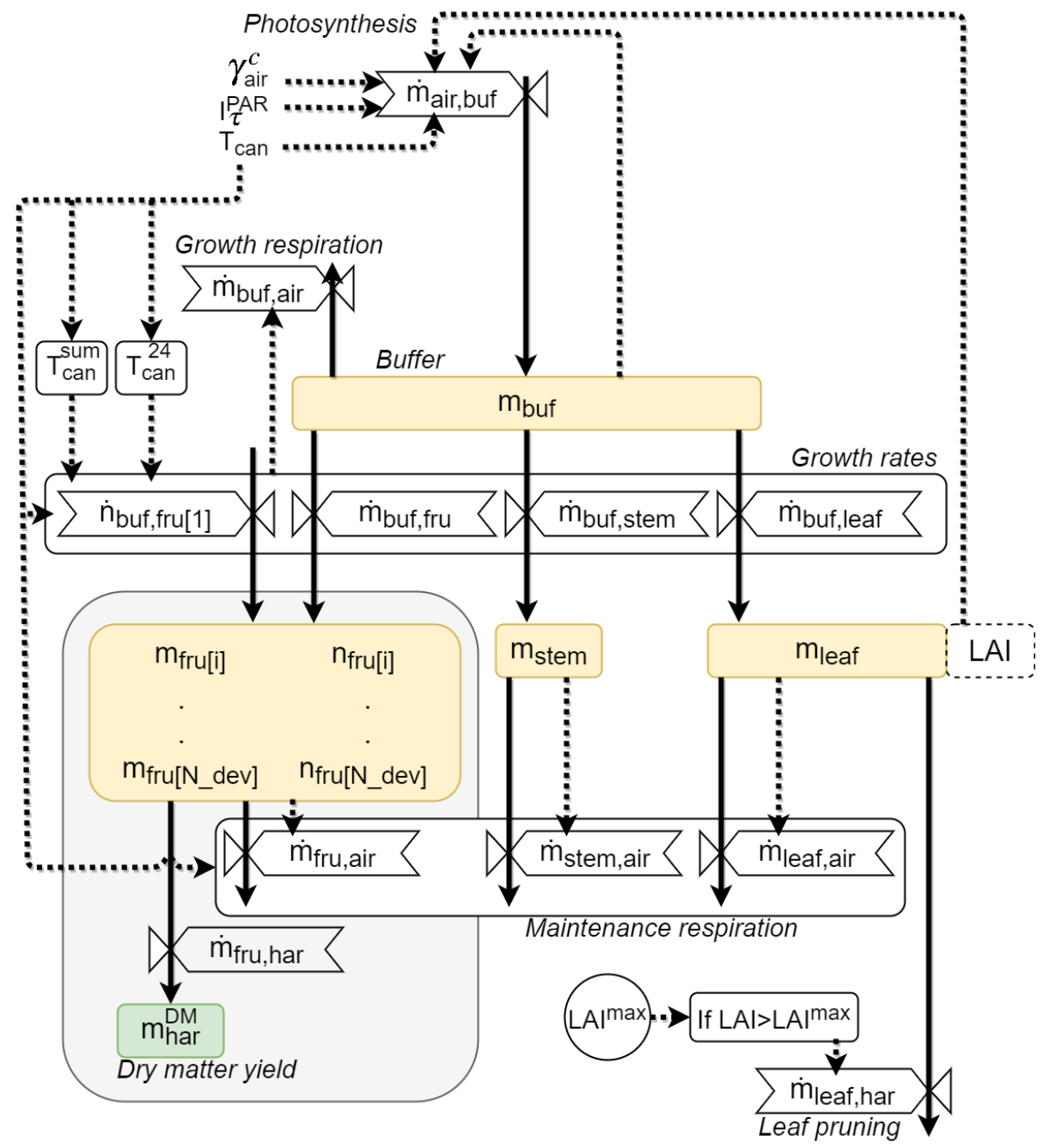

Figure 4: Schematic representation of the tomato yield model. All mass flows and variables are carbohydrate unless stated otherwise. Arrows define mass flows (solid lines) and information flows (dotted lines). Adapted from [37]. 
the two former ones are state variables and the latter one is function of the global irradiation. The distribution flows to the crop parts are function of the buffer state of charge, the growth rate coefficient of each part, two temperature dependent growth inhibition functions (i.e. one for instantaneous and the other for 24-h mean temperature) and the development stage of the plant.

The fruit growth period, defined as the time between fruit set and fruit harvest, is modeled using the "fixed boxcar train" method [38. To that end, several successive development stages are distinguished. The carbohydrate flow from one stage to the next follows a development rate given by the method. At the generative stage of the plant, the carbohydrates are stored in a fruit development stage. For a stage $i$, the stored carbohydrates are described by a mass balance:

$$
\begin{aligned}
& \frac{d m_{f r u[i]}^{c h}}{d t}=\dot{m}_{b u f, f r u[i]}^{c h}+\dot{m}_{f r u[i-1], f r u[i]}^{c h} \\
& -\dot{m}_{f r u[i], f r u[i+1]}^{c h}-\dot{m}_{f r u[i], a i r}^{c h}, \quad i=1,2 \ldots N_{d e v}
\end{aligned}
$$

where $N_{d e v}$ is the total number of fruit development stages. For the first stage $(i=0), \dot{m}_{f r u[i-1], f r u[i]}^{c h}$ is zero. For the last stage $\left(i=N_{d e v}\right), \dot{m}_{f r u[i], f r u[i+1]}^{c h}$ equals to the harvest $\dot{m}_{f r u}^{c h}, h a r$, main output of the model. $\dot{m}_{f r u[i], \text { air }}^{c h}$ is the maintenance fruit respiration of the stage $i$.

Analogous to the carbohydrate flows between stages, the number of fruits from one stage to the next is defined by a development rate given in the method. Its evolution at fruit development stage $i$ is described by:

$$
\frac{d n_{f r u[i]}}{d t}=\dot{n}_{f r u[i-1], f r u[i]}-\dot{n}_{f r u[i], f r u[i+1]}, i=1,2 \ldots N_{d e v}
$$

The amount of carbohydrates stored in the leaves is increased by the distribution from the buffer and decreased by the leaf maintenance respiration and leaf pruning. Its evolution is defined by a mass balance on the leaves, as described by:

$$
\frac{d m_{l e a f}^{c h}}{d t}=\dot{m}_{b u f, l e a f}^{c h}-\dot{m}_{l e a f, a i r}^{c h}-\dot{m}_{l e a f, h a r}^{c h}
$$

The LAI is a semi-state variable of the model that can be determined by the 
specific leaf area (SLA) and the carbohydrates stored in the leaves:

$$
L A I=S L A \cdot m_{\text {leaf }}^{\text {ch }}
$$

The evolution of the carbohydrates stored in the stems and roots is influenced by the distribution from the buffer and the maintenance respiration, as described by:

$$
\frac{d m_{\text {stem }}^{c h}}{d t}=\dot{m}_{b u f, \text { stem }}^{c h}-\dot{m}_{\text {stem, air }}^{c h}
$$

The harvested tomato dry matter (DM) is assumed to evolve with a continuous harvest rate. Therefore, the accumulated DM equals to the carbohydrate outflow from the last fruit development stage converted to DM by a conversion factor, as described by:

$$
\frac{d m_{h a r}^{D M}}{d t}=\xi_{c h \rightarrow D M} \cdot \dot{m}_{f r u, h a r}^{c h}
$$

The development stage of the plant is described by the canopy temperature sum (equation (41)), which allows describing the transition from vegetative to generative stage. Its value is zero when the generative stage starts.

$$
\frac{d T_{c a n}^{\text {sum }}}{d t}=\tau^{-1} \cdot T_{\text {can }}
$$

Finally, the 24 hour mean canopy temperature, used in one growth inhibition function, is determined by a 1st order approach:

$$
\frac{d T_{c a n}^{24}}{d t}=\tau^{-1} \cdot\left(T_{c a n}-T_{c a n}^{24}\right)
$$

For equations (41) and 42, $\tau$ is $86400 \mathrm{~s}$.

\subsection{HVAC and storage models}

This section describes a selection of implemented models for heat distribution, generation and storage.

\subsubsection{Heating distribution system}

The most common heating distribution system in greenhouses is the so-

called pipe rail system, which consists of several parallel pipe loops along the 
crop rows, and is also used as rails for transporting the harvest. An example is shown in Figure 1. Given their rail function, they are plain non-finned pipes and are placed some centimeters above the ground (i.e. below the canopy). To cope with their low heat transfer coefficient, they commonly work at high temperature (between $50^{\circ} \mathrm{C}$ and $90^{\circ} \mathrm{C}$ ). As shown in Figures 2 and 3 , heat is transferred by long-wave radiation to the canopy, the floor and the greenhouse cover, and by hindered convection to the air. Depending on the location and the type of crop, greenhouses may have a smaller secondary low temperature heating circuit placed on top of the canopy.

Because of the importance of temperature-dependent convection and radiation, a constant heat transfer coefficient cannot be assumed along the pipe. A discretized model has therefore been selected. Water flowing through the pipes is modeled using a finite volume approach by means of a discretized model that divides the pipes into several cells, each one connected in series by a node [15]. In each cell, the flow is described with enthalpy as a state variable. The dynamic energy balance and static mass and momentum balances are applied in each cell. The model assumes uniform speed through the cross section as well as constant pressure. Axial thermal energy transfer is neglected. The heat flow is computed by an ideal heat transfer model with constant heat transfer coefficient. The energy balance on the fluid for a cell $i$ is described by:

$$
V_{i} \rho_{i} \frac{d h_{i}}{d t}+\dot{M}\left(h_{e x, i}-h_{s u, i}\right)=A_{i} \dot{q}_{i}, \quad i=1,2 \ldots N_{\text {cell }}
$$

where $h_{i}$ is the fluid specific enthalpy at cell $i$, and $h_{e x}$ and $h_{s u}$ are the enthalpy at the cell's outlet and inlet nodes, respectively.

\subsubsection{Generation unit}

This work proposes a generic CHP model that can be used for different CHP technologies. The CHP is modeled by means of a performance-based model that does not consider part-load operation. Given the latter, the gas consumption is assumed to be constant and follows an On-Off regulation. The unit's total

efficiency is also assumed to be constant. The electrical and thermal powers are 
described by:

$$
\begin{gathered}
\dot{W}=u_{c h p} \cdot \eta_{e l} \cdot \dot{Q}_{g a s} \\
\dot{Q}=u_{c h p} \cdot\left(\eta_{t o t}-\eta_{e l}\right) \cdot \dot{Q}_{g a s}
\end{gathered}
$$

where $u_{C H P}$ is a boolean control variable that defines the operational status of the CHP.

The electrical efficiency is function of the nominal second-law efficiency, which is assumed constant, and the Carnot efficiency, which is function of the high and low temperatures of the cycle. Its value is described by:

$$
\eta_{e l}=\eta_{I I, n} \cdot \eta_{\text {Carnot }}
$$

The nominal value of the second-law efficiency is defined by equation 46 at nominal operation conditions (i.e. the nominal electrical efficiency as well as nominal high and low temperatures of the cycle).

\subsubsection{Thermal energy storage}

Thermal energy storage is modeled by means of a nodal model applied to a stratified tank with an internal heat exchanger. The water tank is modeled using the energy and mass conservation principles and assuming thermodynamic equilibrium at all times inside the control volume. The internal heat exchanger is discretized in the same way as the tank, i.e. each cell of the heat exchanger corresponds to one cell of the tank and exchanges heat with that cell only. The model takes into account ambient heat losses and neglects axial thermal conductivity. The energy balance of the fluid in the heat exchanger is described by equation (43). The energy balance of the fluid in the tank is described by:

$$
\begin{array}{r}
\frac{V^{t e s}}{N_{\text {cell }}} \rho_{i} \frac{d h_{i}}{d t}+\dot{M}\left(h_{e x, i}-h_{s u, i}\right)-A_{h x, i} \dot{q}_{h x, i}=\frac{A_{a m b}}{N_{c e l l}} \dot{q}_{a m b} \\
i=1,2 \ldots N_{\text {cell }}
\end{array}
$$

where $A_{a m b}$ is the total heat exchange area from the tank to the ambient. 


\subsection{Climate control}

In order to maximize crop yield, greenhouses have strict requirements on indoor climate control. The climate controller adjusts heating, ventilation and $\mathrm{CO}_{2}$ supply to attain the desired climate. In this work, several control systems are proposed and implemented.

\subsubsection{Climate set-points definition}

The determination of temperature and $\mathrm{CO}_{2}$ set-points is key to maximize photosynthesis and thus the harvest. As measured in [39], different combinations of temperature and $\mathrm{CO}_{2}$ levels for a given radiation level lead to different photosynthesis rates. Moreover, although a sharp reduction in photosynthesis rate is measured at non-optimal temperatures, similar rates are measured for close-to-optimal temperatures (i.e. optimal temperature $\pm 3^{\circ} \mathrm{C}$ ). This allows selecting set-points that not only maximize photosynthesis rate but also minimize energy consumption.

The definition of temperature set-points for optimal crop growth and energy use has been the subject of a substantial literature (e.g. [40, 41, 42, 43]). However, since this work does not focus on climate set-points optimization, the strategy proposed in 41] is adopted and implemented. The strategy consists in selecting the pair of temperature and $\mathrm{CO}_{2}$ levels at a given radiation level that minimizes energy consumption while maintaining a close-to-maximal crop growth rate. This is achieved by the following process:

i) computing a 2-D table of photosynthesis rates at a given PAR for a range of $\mathrm{CO}_{2}$ and temperature values,

ii) selecting from the table the pairs of $\mathrm{CO}_{2}$ and temperature that ensure at least $80 \%$ of the photosynthesis rate (the $100 \%$ being the maximum value of the 2-D array), and

iii) defining the temperature and $\mathrm{CO}_{2}$ set-point $\left(T_{a i r, S P}, \gamma_{\text {air, SP }}^{c}\right)$ as the pair in ii) with the lowest temperature. 
In the model, a proportional integer (PI) controller ensures that the air temperature set-point is respected by adjusting the power output of the heating system. A second PI controller ensures that the $\mathrm{CO}_{2}$ set-point is respected by adjusting the supply from the enrichment system. Given that $\mathrm{CO}_{2}$ is an expensive resource, in high ventilation conditions the set-point is modified so that it decreases proportionally with the increase in the ventilation rate. This is done as defined by equations 48 and 49 .

$$
\begin{aligned}
\gamma_{a i r, S P^{\prime}}^{c} & =\eta_{\text {ven }}\left(\gamma_{a i r, S P}^{c}-\gamma_{a i r, S P}^{c, m i n}\right)+\gamma_{a i r, S P}^{c, m i n} \\
\eta_{v e n} & = \begin{cases}1-\frac{u_{v e n}}{u_{v e n}^{\max },} & \text { if } u_{v e n}<u_{v e n}^{\max } \\
0, & \text { otherwise }\end{cases}
\end{aligned}
$$

\subsubsection{Supplementary lighting}

In this work, the lighting model parameters correspond to HPS lamps, which are the most used commercial type of lamp in horticulture because of their high emission in the PAR spectrum range. The control strategy is based on the following conditions and rules:

- Time window: allow lights to be turned On during a time window $\left(t_{\text {start }}\right.$, $\left.t_{\text {end }}\right)$, e.g. from $5 \mathrm{AM}$ to $10 \mathrm{PM}$.

- Threshold: during the time window, allow lights to be turned On if the level of transmitted short-wave radiation decreases below a threshold $\left(I_{O f f \rightarrow O n}\right)$ and to be turned Off if it increases above a threshold $\left(I_{O n \rightarrow O f f}\right)$, with $I_{O n \rightarrow O f f}>I_{O f f \rightarrow O n}$.

- Proving time: the level of transmitted radiation must be above or below the threshold for a certain time $\left(t_{\text {prove }}\right)$ before acting.

- Maximum accumulation: turn Off lights or do not allow turning them On if the daily accumulated short-wave radiation exceeds a threshold $\left(I_{a c c}^{\max }\right)$.

- Minimum time On: to prevent cycling, which dramatically reduces the lamp lifespan, lights must remain On for a minimum time $\left(t_{O n}^{\min }\right)$ once they are turned On, regardless of other conditions. 


\subsubsection{Windows}

In greenhouse climate control, windows are opened for two different purposes. The first is dehumidification, since excessive humidity can cause fungal diseases or physiological disorders to the canopy [44]. The most common technique for dehumidification is natural ventilation with the outside air, which requires heating to maintain the indoor temperature at the set-point. Although this technique is energy consuming and thus expensive, dehumidifying systems based on refrigerant cycles, e.g. heat pumps, have not yet proved to be economically feasible [31]. The second purpose is cooling the indoor air in case of excessive temperature, since this has a negative impact on the harvest rate. For instance, in [37], the harvest rate at daytime temperatures of $40^{\circ} \mathrm{C}$ was only $54.5 \%$ of that at $25^{\circ} \mathrm{C}$. In addition, temperatures above $25^{\circ} \mathrm{C}$ can penalize fruit quality e.g. size and color [31].

In the model, a PI controller selects the opening of the windows depending on the purpose:

- Air sanitation: when humidity exceeds a threshold $\left(R H_{v e n}\right)$, set by the user (commonly 85\%).

- Air cooling: when air temperature exceeds a threshold $\left(T_{v e n}\right)$, which can be variable in function of for instance outside temperature.

\subsubsection{Thermal screen}

As previously mentioned, the thermal screen is an horizontally movable membrane used to limit the far-infrared radiative losses to the cover and to the sky. When deployed, these losses can be reduced by $38 \%$ to $60 \%$ [45]. This capability is defined by the screen material, which is mainly selected according to the climate of the region where the greenhouse is located. The selected material also implies a certain short-wave transmission coefficient, whose value can vary from $88 \%$ to $15 \%$.

Deployment set-point. Since the screen reduces considerably the transmitted light, the most conventional method to operate the screen is to open it at sunrise, 
to benefit from the available sunlight, and to draw it at sunset, when heating demand becomes significant.

A possibility to further reduce energy consumption is to deploy the screen before sunset and to delay the opening until after sunrise. However, this method implies a loss of crop production caused by a reduction on the available light. Determining the optimal tradeoff between energy saving and production loss in terms of deployment and opening times has been the object of several studies (e.g. [41, 45]). It is however a complex task, subject to multiple uncertainty sources are requiring multiple assumptions.

A simpler approach is to define the deployment of the screen in function of the sole outside irradiation. This is justified by the fact that the photosynthetic activity of the plant achieves its maximal potential about one hour after sunrise and diminishes just before sunset [46].

In this work, a hybrid approach has been selected, where the deployment of the screen is defined by an outside temperature-dependent radiation criterion. This method promotes energy savings in cold, cloudy days and avoids overheating in warm mornings, which is an improvement compared to the radiation-only dependent approach.

Deployment strategy. In order not to generate cold air flows on top of the canopy, the screen is removed progressively until reaching a certain gap size, from which it can be fully removed. For instance, in mild conditions, a screen is typically removed progressively at around $1 \%$ per minute (with an interval pause of 3 minutes) followed by a full removal after $30 \%$. The duration of this process can be adapted to the outside weather. For instance, in Dutch-conditions this process can last about $45 \mathrm{~min}$ to $60 \mathrm{~min}$ in cold days and $30 \mathrm{~min}$ in mild days [46]. The same applies for the screen deployment.

In the model, the duration of the process $\left(t_{\text {open }}\right)$ and the gap size from which the screen can be removed completely $\left(u_{\text {scr,open }}\right)$ are defined as adjustable parameters. In order to avoid the computational overhead linked to events during the simulation [47, the removal/deployment processes are not performed 
step-wise but continuously.

Humidity gap. It is common during night-time to perform small temporary openings of the vents to decrease the relative humidity in the main air zone. As for the deployment strategy, to maintain a sufficient computational efficiency, the humidity gap is not controlled step-wise (as proposed in 48]) but continuously. This is done by means of a PI controller, which compares the actual humidity value to a set-point $\left(R H_{\text {gap }}\right)$. The control signal ranges between no gap to a maximum gap value set by the user.

In a similar way, a small opening may be required because of temperature excess. This opening is also controlled by a PI controller, whose set-point $\left(T_{g a p}\right)$ is set some degrees above the indoor air set-point.

\section{Case study}

In this work, various energy management strategies are defined and simulated to demonstrate the capabilities of the proposed modeling framework. To that end, a tomato-growing greenhouse is selected as case study. The greenhouse is connected to a thermal energy storage unit and to a CHP unit. A simplified scheme of the system is shown in Figure 5. The generated heat can be either stored in a large water tank or directly bypassed to the greenhouse heating distribution circuit. In order to obtain an horizontally-homogeneous indoor climate, the heat input to the greenhouse is controlled by temperature regulation. A three way valve is used for that purpose, allowing to mix the return to lower down the supply temperature. The generated electricity from the CHP can either be self-consumed or fed back to the grid.

The model is parametrized according to the case study. The selected greenhouse has a Venlo-type structure with a single glass layer cover, typical for mild-temperature conditions. The floor area is 2.3 ha. Ventilation only occurs naturally through the roof windows. Heating is distributed by a pipe rail system. The greenhouse is equipped with a $\mathrm{CO}_{2}$ enrichment system, HPS lamps and a movable thermal screen. No cooling equipment is considered. The design 


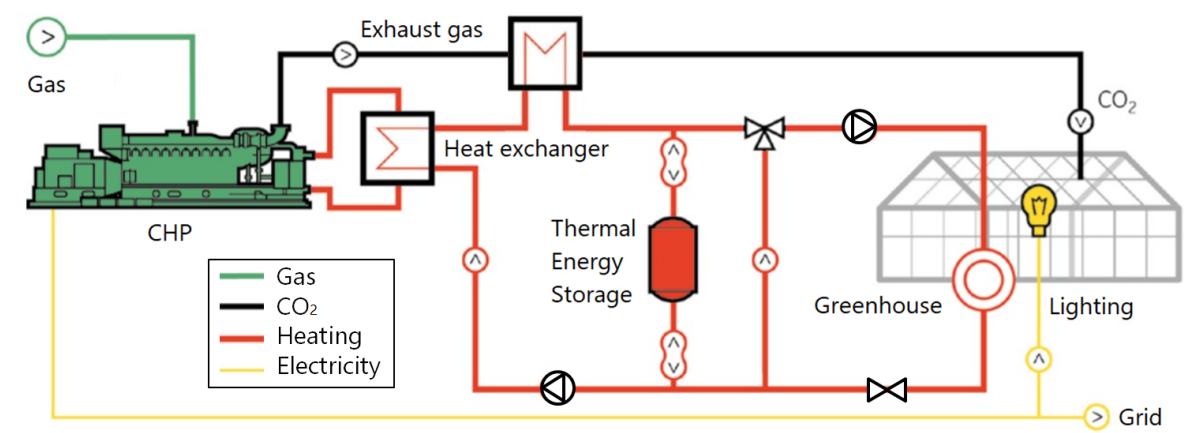

Figure 5: Scheme of the simulation model (adapted from [49])

parameters related to the greenhouse construction, ventilation, heating, $\mathrm{CO}_{2}$ enrichment and supplementary lighting are presented in Table 2 The climate controller actions are based on the strategies presented in Section 2.4 , whose inputs are presented in Table 3 .

Table 2: Main parameters of the model.

\begin{tabular}{lll}
\hline Parameters & Value & Units \\
\hline Construction & & \\
$A_{\text {flr }}$ & $2.3 \cdot 10^{4}$ & $\mathrm{~m}^{2}$ \\
$\varphi_{\text {cov }}$ & 25 & $\circ$ \\
$h_{\text {air }}$ & 3.8 & $\mathrm{~m}$ \\
$h_{\text {gh }}$ & 4.2 & $\mathrm{~m}$ \\
\hline Cover & & \\
$\varepsilon_{\text {cov }}$ & 0.85 & - \\
$\rho_{\text {cov }}^{N I R}$ & 0.13 & - \\
$\rho_{\text {cov }}^{P A R}$ & 0.13 & - \\
$\tau_{\text {cov }}^{N I R}$ & 0.85 & - \\
$\tau_{\text {cov }}^{P A R}$ & 0.85 & - \\
$c_{\text {cov }}$ & 840 & $\mathrm{~J} \mathrm{~K}^{-1} \mathrm{~kg}^{-1}$ \\
$\rho_{\text {cov }}$ & 2600 & $\mathrm{~kg} \mathrm{~m}^{-3}$ \\
$e_{\text {cov }}$ & $4 \cdot 10^{-3}$ & $\mathrm{~m}$ \\
\hline
\end{tabular}




\begin{tabular}{|c|c|c|}
\hline Parameters & Value & Units \\
\hline \multicolumn{3}{|c|}{ Thermal screen } \\
\hline$\varepsilon_{s c r}$ & 0.67 & - \\
\hline$\rho_{s c r}^{N I R}$ & 0.35 & - \\
\hline$\rho_{s c r}^{P A R}$ & 0.35 & - \\
\hline$\tau_{s c r}^{N I R}$ & 0.6 & - \\
\hline$\tau_{s c r}^{P A R}$ & 0.6 & - \\
\hline$c_{s c r}$ & 1800 & $\mathrm{~J} \mathrm{~K}^{-1} \mathrm{~kg}^{-1}$ \\
\hline$\rho_{s c r}$ & 200 & $\mathrm{~kg} \mathrm{~m}^{-3}$ \\
\hline$e_{s c r}$ & $0.35 \cdot 10^{-3}$ & $\mathrm{~m}$ \\
\hline$K_{s c r}$ & $0.05 \cdot 10^{-3}$ & $\mathrm{~m}^{3} \mathrm{~m}^{-2} \mathrm{~K}^{-0.66} \mathrm{~s}^{-1}$ \\
\hline \multicolumn{3}{|l|}{ Floor } \\
\hline$\varepsilon_{f l r}$ & 1 & - \\
\hline$\rho_{f l r}^{N I R}$ & 0.5 & - \\
\hline$\rho_{f l r}^{P A R}$ & 0.65 & - \\
\hline$\lambda_{f l r}$ & 1.7 & $\mathrm{~W} \mathrm{~m}{ }^{-1} \mathrm{~K}^{-1}$ \\
\hline$c_{f l r}$ & 880 & $\mathrm{~J} \mathrm{~K}^{-1} \mathrm{~kg}^{-1}$ \\
\hline$\rho_{f l r}$ & 2300 & $\mathrm{~kg} \mathrm{~m}^{-3}$ \\
\hline$e_{f l r}$ & 0.02 & $\mathrm{~m}$ \\
\hline \multicolumn{3}{|l|}{ Soil } \\
\hline$\lambda_{s o}$ & 0.85 & $\mathrm{~W} \mathrm{m^{-1 }} \mathrm{K}^{-1}$ \\
\hline$\rho \cdot c_{s o}$ & $1.73 \cdot 10^{6}$ & $\mathrm{~J} \mathrm{~K}^{-1} \mathrm{~m}^{-3}$ \\
\hline \multicolumn{3}{|l|}{ Canopy } \\
\hline$\varepsilon_{c a n}$ & 1 & - \\
\hline$U_{\text {leaf,air }}$ & 5 & $\mathrm{~W} \mathrm{~m}^{-2} \mathrm{~K}^{-1}$ \\
\hline \multicolumn{3}{|l|}{ Ventilation } \\
\hline$A_{v e n} / A_{f l r}$ & 0.1 & $\mathrm{~m}^{2}$ \\
\hline$K_{d}$ & 0.75 & - \\
\hline$K_{w}$ & 0.09 & - \\
\hline$K_{\text {leak }}$ & $1 \cdot 10^{-4}$ & - \\
\hline
\end{tabular}




\begin{tabular}{lll}
\hline Parameters & Value & Units \\
\hline$h_{\text {ven }}$ & 0.68 & $\mathrm{~m}$ \\
\hline Heating & & \\
$d_{\text {pip }}$ & 0.051 & $\mathrm{~m}$ \\
$l_{\text {pip }}$ & 1.36 & $\mathrm{~m} \mathrm{~m}^{-2}$ \\
\hline CO $_{2}$ supply & & \\
$\dot{m}_{\text {ext }}^{\text {c,max }}$ & 7.5 & $\mathrm{mg} \mathrm{m}^{-2} \mathrm{~s}^{-1}$ \\
\hline Supp. lighting & & \\
$P_{\text {el }}$ & 100 & $\mathrm{~W} \mathrm{~m}^{-2}$ \\
\hline External systems & & \\
$V^{\text {tes }}$ & 1100 & $\mathrm{~m}^{3}$ \\
$\dot{Q}_{\text {gas }}^{\text {chp }}$ & 3.92 & $\mathrm{MW}^{\text {chp }}$ \\
$\eta_{\text {el }}^{\text {chp }}$ & 0.4 & - \\
\hline tot & 0.9 & - \\
\hline
\end{tabular}

The tomato yield model is run simultaneously with the greenhouse climate model. The crop initial conditions are shown in Table 3

The CHP unit has a nominal capacity of $3.92 \mathrm{MW}$. The nominal electrical and thermal efficiencies are $40 \%$ and $50 \%$, respectively. The thermal efficiency lumps the heat provided directly by the CHP and heat recovered from the exhaust gases. The storage volume is $1100 \mathrm{~m}^{3}$.

The simulation period is one year and starts on December 10th, being equivalent to the start period for tomato growth in mild-climate conditions. Data for a typical meteorological year (TMY) in Brussels is used to describe the outdoor conditions, namely air temperature, relative humidity, pressure, wind speed and global irradiation.

In order to demonstrate the capabilities of the model, two sensitivity analyses with different energy management strategies are performed. The first intends to show the difference in energy consumption and the impact on crop growth caused by applying different control rules on the greenhouse thermal screen. To 
Table 3: Main inputs of the model

\begin{tabular}{lll}
\hline Parameters & Value & Units \\
\hline Crop conditions & & \\
$L A I^{\text {max }}$ & 2.7 & $\mathrm{~m}^{2} \mathrm{~m}^{-2}$ \\
$L A I^{0}$ & 0.3 & $\mathrm{~m}^{2} \mathrm{~m}^{-2}$ \\
$m_{\text {leaf }}^{\text {ch }}$ & $40 \cdot 10^{3}$ & $\mathrm{mg}\left\{C \mathrm{H}_{2} O\right\} \mathrm{m}^{-2}$ \\
$m_{\text {stem }}^{\text {ch }}$ & $30 \cdot 10^{3}$ & $\mathrm{mg}\left\{\mathrm{CH}_{2} O\right\} \mathrm{m}^{-2}$ \\
\hline
\end{tabular}

\section{Climate control}

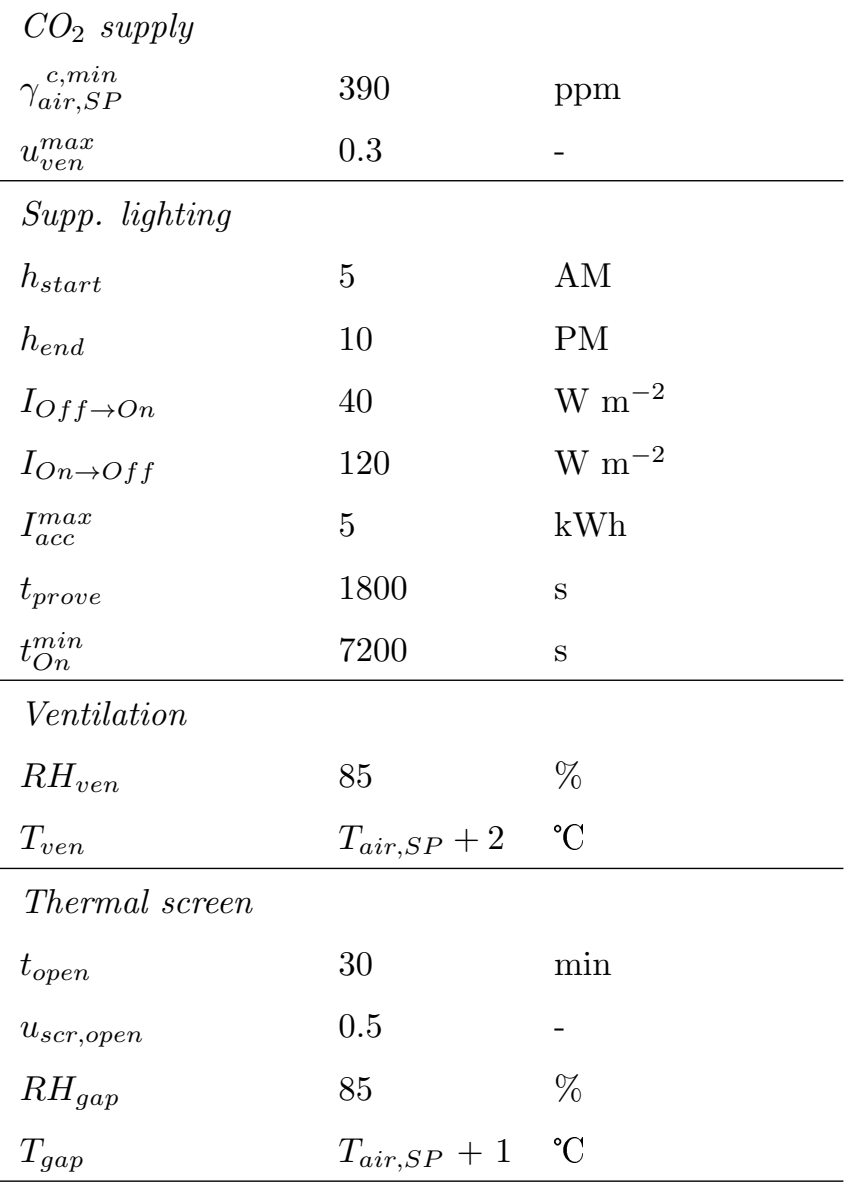

Energy prices

\begin{tabular}{lll}
$\pi_{\text {gas }}$ & 35.5 & $\in \mathrm{MWh}^{-1}$ \\
$\pi_{\text {el }}^{\text {buy }}$ & 141.5 & $\in \mathrm{MWh}^{-1}$ \\
$\pi_{e l}^{\text {sell }}$ & 47.2 & $\in \mathrm{MWh}^{-1}$ \\
\hline
\end{tabular}


that end, three different deployment methods are tested:

- C05: The first and simpler approach, consists in deploying and removing the screen at sunset and sunrise. In the model, these are set at the threshold of $5 \mathrm{~W} \mathrm{~m}^{-2}$.

- C30: given that photosynthetic activity of the plant achieves its maximal potential about one hour after sunrise and diminishes just before sunset [46, the second approach consists in remomving the screen after outside irradiation reaches $30 \mathrm{~W} \mathrm{~m}^{-2}$.

- VAR: The third approach consists in deploying the screen in function of an outside temperature dependent radiation criterion. As shown in Figure 6. the screen is removed when crossing the following threshold:

$$
I_{\text {thr }}^{G}=\max \left\{0,290-19.33 \cdot T_{\text {out }}\right\}
$$

where $T_{\text {out }}$ is expressed in Celsius. In other words, the screen is open/deployed when the combination of outside temperature and solar radiation is above/below the set-point.

The second study intends to show the difference on the system operational cost for different controls on the CHP unit. The operational cost is obtained by:

$$
C_{t o t}=C_{g a s}^{c h p}+C_{e l}^{b u y}-B_{e l}^{\text {sell }}
$$

where $C_{g a s}^{c h p}$ is the gas cost, $C_{e l}^{b u y}$ is the cost of the electricity consumed from the grid and $B_{e l}^{\text {sell }}$ is the remuneration from the electricity fed back to the grid. Electricity is purchased if there is an electrical demand and the CHP is not running, or the system is short (i.e. the CHP is running but its output power is lower than the consumption). In a similar manner, electricity is fed back if the system is long. In the absence of subsidies, fed back electricity is remunerated at a price close to the wholesale price of electricity. Given that the retail price of electricity is significantly higher than the wholesale price, prosumers have a clear advantage at maximizing their level of self-consumption [50]. To evaluate 
the impact this can have on the total operational cost, three state diagram controls are implemented:

- Heat-driven control (HDC): This control ensures the heating demand regardless of the electrical demand. The CHP is run to heat up the TES and/or to provide the greenhouse heating demand. Since there is heating demand almost every day of the year, the TES is not allowed to go below a certain temperature. Its storage level is controlled by keeping the temperature at the middle cell in between boundaries.

- Electrical-driven control (EDC): This control maximizes electrical selfconsumption regardless of the heating demand. The CHP is operated only when there is an electrical consumption, i.e. when the lamps are turned On. As explained in Section 2.4.2, the lower the solar radiation, the higher the hours the lamps operate and viceversa. Therefore, the EDC runs the CHP for longer periods in the days with a lower heat input from the sun, i.e. the days with a higher heating demand.

- Mix-driven control (MDC): This control maximizes electrical self-consumption while ensuring the heating demand. The CHP can be operated by the EDC or the HDC. Therefore, the CHP is always run when the lamps are On, and can also be started up if the lamps are Off but the conditions of the HDC are satisfied.

The gas and electrical prices used for this study are stated in Table 3 . All simulations of the first sensitivity analysis use the HDC. Simulations of the second sensitivity analysis use the VAR set-point in the screen control. Therefore, there are a total of five simulations (VAR and HDC being the same).

\section{Results and discussion}

\subsection{Optimizing screen use}

Table 4 summarizes some key results obtained for the C05, C30 and VAR simulations. The first three columns evaluate the share of time over the total simulation time during which the air temperature is: 
- $t_{i n}$ : well controlled $\left(T_{a i r}\right.$ in $\left.T_{a i r, S P} \pm 1.5^{\circ} \mathrm{C}\right)$

- $t_{u h}$ : underheated $\left(T_{a i r}<T_{a i r, S P}-1.5^{\circ} \mathrm{C}\right)$

- $t_{o h}$ : overheated $\left(T_{a i r}>T_{a i r, S P}+1.5^{\circ} \mathrm{C}\right)$

Table 4: Main results of the sensitivity analysis on screen use

\begin{tabular}{lllllll}
\hline & $\begin{array}{c}t_{\text {in }} \\
{[\%]}\end{array}$ & $\begin{array}{l}t_{u h} \\
{[\%]}\end{array}$ & $\begin{array}{l}t_{\text {oh }} \\
{[\%]}\end{array}$ & $\begin{array}{l}E_{\text {th }}^{g h} \\
{\left[\mathrm{kWh} \mathrm{m}^{-2}\right]}\end{array}$ & $\begin{array}{l}E_{\text {el }}^{g h} \\
{\left[\mathrm{kWh} \mathrm{m}^{-2}\right]}\end{array}$ & $\begin{array}{l}m_{\text {har }}^{D M} \\
{\left[\mathrm{~kg} \mathrm{~m}^{-2}\right]}\end{array}$ \\
\hline C05 & 75.6 & 0.55 & 23.9 & 373.4 & 227.4 & 4.74 \\
C30 & 75.8 & 0.65 & 23.6 & 362.6 & 227.4 & 4.72 \\
VAR & 76.9 & 0.64 & 22.5 & 356.9 & 227.4 & 4.58 \\
\hline
\end{tabular}

By looking at the numbers in Table 4 one can see the air temperature control has similar efficiencies for the three simulations. This is justified by a fast control, which adapts the heating input and the opening of the windows to the constantly changing dynamics. Independent of the screen operation, the control manages to keep the air temperature well controlled for in average $76 \%$ of the time. The rest of the time, the greenhouse climate is rarely underheated (less than $1 \%$ of the time) and mostly overheated (in average $23 \%$ of the time). Although overheating can be caused by an excessive input from the heating units, it is primarily caused by excessive solar gains. In mild-weather regions like Belgium, the temperature inside the greenhouse can reach $40^{\circ} \mathrm{C}$ in hot sunny days. As quantified in Section 2.4.3, excessive temperatures have a negative impact on the harvest rate and must be avoided. However, since this event only occurs occasionally, investing in a cooling system is not justified.

As previously stated, in order to keep the temperature within boundaries, the climate control adapts the heating input and the opening of the windows. Simulation C05 has therefore the highest heating consumption $\left(373 \mathrm{kWh} \mathrm{m}^{-2}\right)$. Delaying the opening from 5 to $30 \mathrm{~W} \mathrm{~m}^{-2}$ in C30, allows decreasing the heating consumption by $2.9 \%$ without penalizing crop growth (-0.5\% of harvested DM). Moreover, the outside temperature dependent radiation criterion (VAR) allows 
decreasing heating consumption by $4.4 \%$ but at the expense of a more significant decrease in harvested DM (-3.3\%). The screen opening for each simulated point of the latter control strategy are plotted in Figure 6. It should be noticed that the screen is never closed above the threshold, but it is sometimes open below it (i.e. blue points below the $I_{t h r}^{G}$ curve). These points do not reflect a control failure but instead, follow the humidity control, which is at the top of the screen control hierarchy.

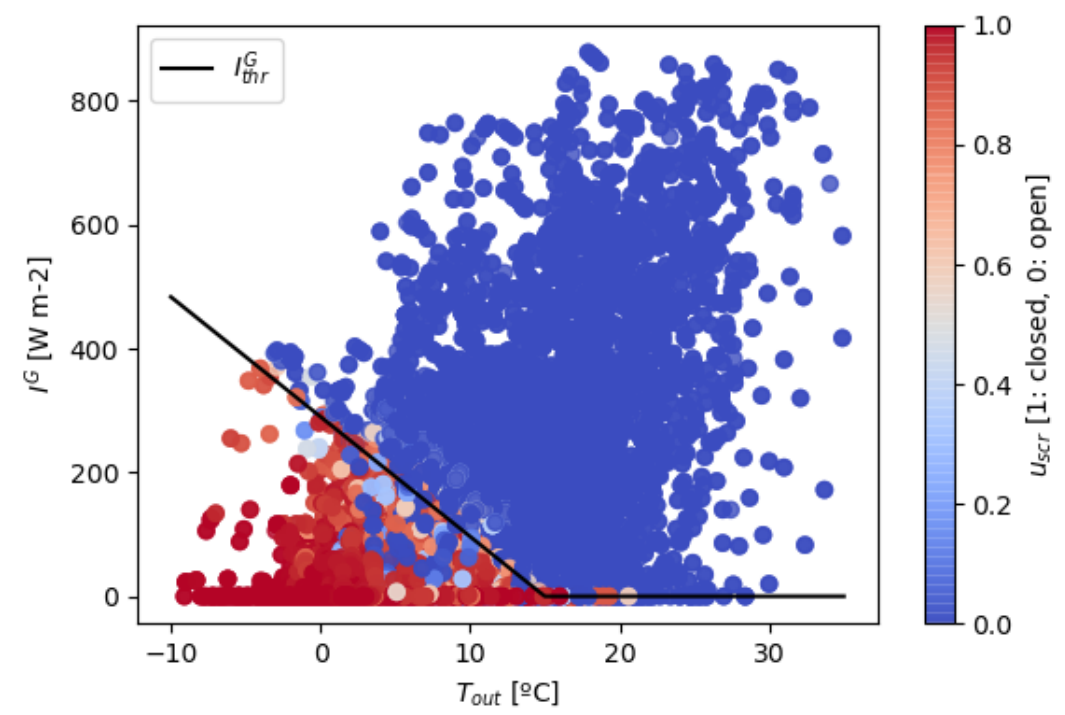

Figure 6: VAR's screen deployment criterion $\left(I_{t h r}^{G}\right)$ and simulation points

Overall, the VAR method is an improved version of the simpler radiationonly dependent approaches (C05 and C30) by promoting energy savings in cold cloudy days and avoiding overheating in warm mornings.

\subsection{Optimizing operational costs}

Some key characteristics of the results obtained for the heat, electrical and mix-driven controls are presented in Table 5. The HDC and MDC present similarities in terms of performance. They succeed in controlling indoor temperature during $76.9 \%$ and $76.1 \%$ of the simulation period, respectively. The greenhouse 
is underheated during only $0.64 \%$ and $0.67 \%$ of the total time, the remainder $22.5 \%$ and $23.2 \%$ of the time is overheated. The EDC, on the contrary, keeps the temperature within boundaries during only $46 \%$ of the time. Running the CHP only in case of electrical demand (i.e. 2233 hours, corresponding to hours of supplementary lighting) is not sufficient to fulfill the heating demand. The greenhouse is underheated $44 \%$ of the time.

Table 5: Main results of the sensitivity analysis on operational costs

\begin{tabular}{|c|c|c|c|c|c|c|c|c|c|c|c|c|}
\hline & $\begin{array}{l}t_{\text {in }} \\
\text { [\%] }\end{array}$ & $\begin{array}{l}t_{u h} \\
{[\%]}\end{array}$ & $\begin{array}{l}t_{o h} \\
{[\%]}\end{array}$ & $\begin{array}{l}E_{\text {gas }}^{c h p} \\
{[\mathrm{MWh}]}\end{array}$ & $\begin{array}{l}E_{t h}^{c h p} \\
{[\mathrm{MWh}]}\end{array}$ & $\begin{array}{l}E_{e l}^{c h p} \\
{[\mathrm{MWh}]}\end{array}$ & $\begin{array}{l}E_{e l}^{b u y} \\
{[\mathrm{MWh}]}\end{array}$ & $\begin{array}{l}E_{e l}^{\text {sell }} \\
{[\mathrm{MWh}]}\end{array}$ & $\begin{array}{l}C_{\text {gas }} \\
{[\mathrm{k} €]}\end{array}$ & $\begin{array}{l}C_{e l}^{b u y} \\
{[\mathrm{k} \in]}\end{array}$ & $\begin{array}{l}B_{\text {el }}^{\text {sell }} \\
{[\mathrm{k} €]}\end{array}$ & $\begin{array}{l}C_{t o t} \\
{[\mathrm{k} \in]}\end{array}$ \\
\hline HDC & 76.9 & 0.642 & 22.5 & 16477 & 8271 & 6509 & 3413 & 4691 & 585 & 483 & 221 & 846 \\
\hline MDC & 76.1 & 0.671 & 23.2 & 16820 & 8408 & 6680 & 1826 & 3276 & 597 & 258 & 155 & 700 \\
\hline $\mathrm{EDC}$ & 46.0 & 44.0 & 9.94 & 8754 & 4321 & 3558 & 1672 & 0.125 & 311 & 237 & 0.006 & 547 \\
\hline
\end{tabular}

In terms of operational strategy, the HDC and MDC run the CHP unit for a similar accumulated time (4 203 and 4291 hours, respectively) and thus, have similar gas consumptions. However, the time of the day where the CHP is run differs for both controls. Its impact is mainly reflected in the electrical consumption. For instance, the HDC runs the CHP independently of the operation of supplementary lighting. The generated electricity is therefore either consumed or sold depending on the lighting status at the moment. From the generated $6509 \mathrm{MWh}_{e l}$, only $28 \%$ is consumed by the greenhouse, the rest $4691 \mathrm{MWh}_{e l}$ being fed back to the grid and remunerated at $221 \mathrm{k} \in$. To cover the greenhouse electrical demand, this leads to $3413 \mathrm{MWh}_{e l}$ bought from the grid with an associated cost of $483 \mathrm{k} \in$. Considering the gas cost, the final operational cost at the end of the simulation period is $846 \mathrm{k} €$.

By prioritizing the operation of the CHP during supplementary lighting hours, the MDC allows decreasing the amount of electricity bought from the grid by $46 \%$ with respect to the HDC, saving $225 \mathrm{k} \in$. Nonetheless, since the instant power produced by the CHP is smaller than the electrical consumption of the lamps, the system is often short and the remainder 54\% (1826 $\mathrm{MWh}_{e l}$ ) are still bought from the grid. Since the CHP is also run when lamps are Off 
because of heat-driven conditions, the MDC feeds back to the grid $3276 \mathrm{MWh}_{e l}$, which are remunerated at $155 \mathrm{k} \in$. This is $49 \%$ of its electrical production, compared to $72 \%$ in the HDC. In total, the operational cost of the MDC at the end of the simulation period is $700 \mathrm{k} \in$. Therefore, compared to the HDC the MDC allows reducing total operational costs by $17 \%$.

Figure 7 shows three Sankey diagrams of the accumulated energy flows in the MDC simulation for the whole simulation period, the month of January and the month of July. By comparing the diagrams, it appears that only $1.8 \%$ of the yearly solar radiation is received in January, versus $16 \%$ in July. For January, this implies a higher use of heating ( $12 \%$ of the yearly consumption, versus $5 \%$ in July) and a higher use of supplementary lighting (15\% of the yearly consumption, versus $1.9 \%$ in July).

As expected, most of the energy losses happen through long-wave radiative heat transfer with the sky, by convection from the outer side of the cover or by ventilation from the indoor air to the outside air. In January, ventilation is limited and the loss by convection from the cover is substantial. On the contrary, in July, ventilation is used intensively to decrease the indoor air temperature.

Latent heat gains from condensation on the inner side of the cover mainly occur in January due to the cold outside air. In July, condensation is minimal in the greenhouse. However, the canopy is warmer than the air and has high latent heat losses due to transpiration. In January, on the contrary, given the smaller short-wave radiation intake (among others), the canopy is colder than the air and presents lower latent heat losses.

Finally, it should be remarked that the screen is a key participant in the sensible energy balance in January, whereas it is barely participating in July.

\section{Conclusions}

The presented modeling framework is dedicated to the energy management and system integration of greenhouses. It gathers in a single library relevant models accounting for crop yield, greenhouse climate simulation, heat and power 


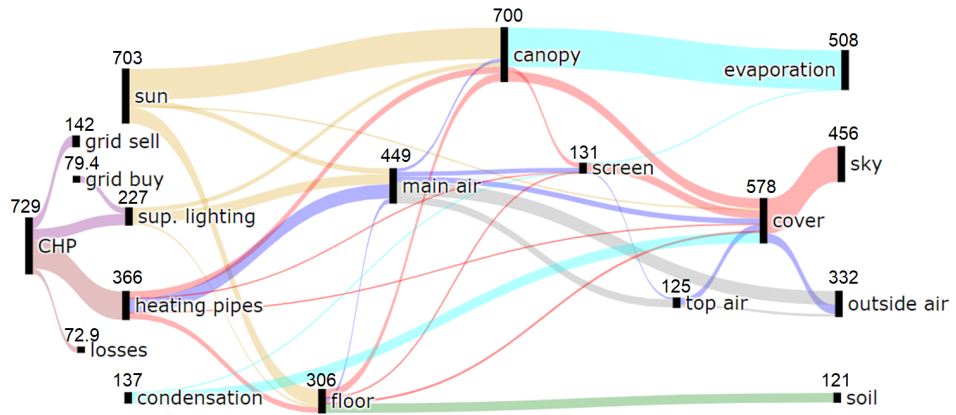

(a) Year

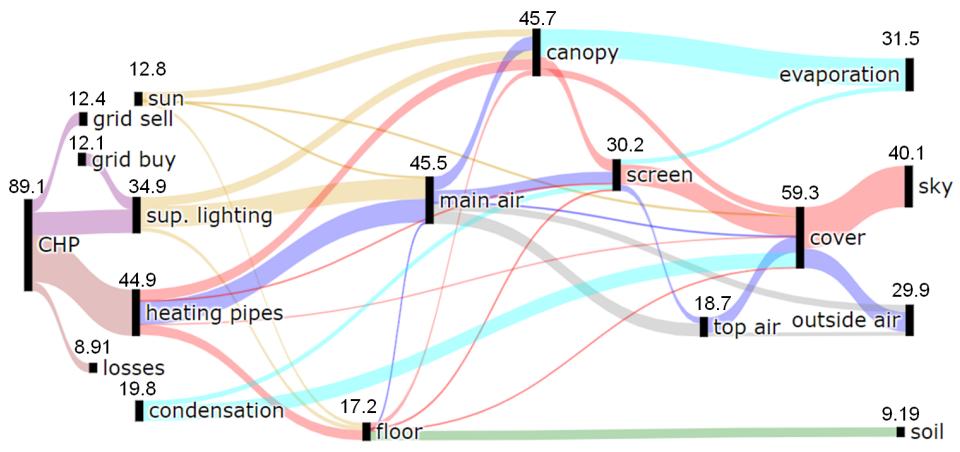

(b) January

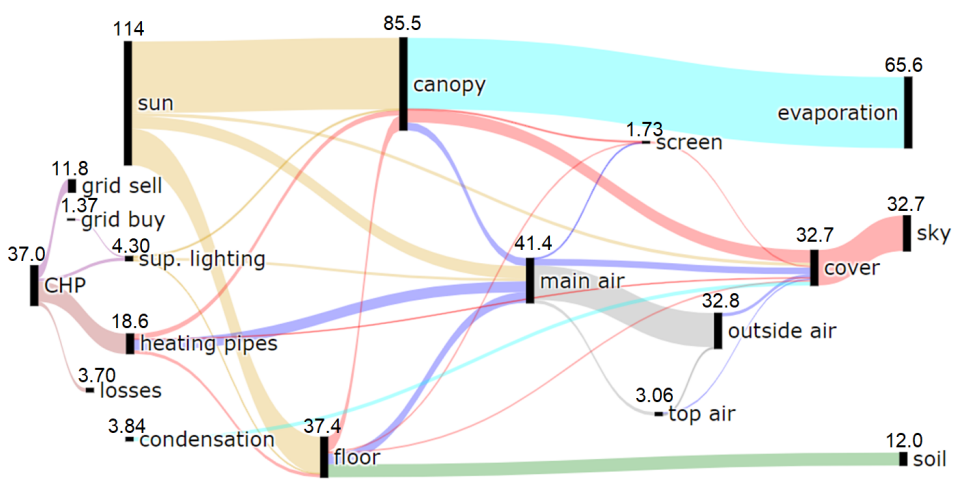

(c) July

$\begin{array}{lll}\text { Electrical energy }\left(E_{e l}\right) & \text { Long-wave radiation }\left(E^{\text {rad }}\right) & \text { Conduction }\left(E^{\text {cnd }}\right) \\ \text { Thermal energy }\left(E_{t h}\right) & \text { Convection }\left(E^{\text {cnv }}\right) & \text { Latent heat }\left(E^{\text {lat }}\right) \\ \text { Short-wave radiation }\left(E^{\text {swr }}\right) & \text { Ventilation }\left(E^{\text {sens }}\right) & \end{array}$

Figure 7: Sankey diagrams of the accumulated sensible energy flows in the MDC simulation 
generation units and greenhouse control systems. The framework is released as open-source, thus ensuring a proper reproducibility and reusability of this work [51] (Download from: https://github.com/queraltab/Greenhouses-Library).

The parametric, object-oriented approach offers a high degree of flexibility to the user. The model can easily be adapted to meet different greenhouse designs by parametrizing the existing components (e.g. floor material, type of cover, capacities of the HVAC systems, etc.) or even to add other components (e.g. the addition of secondary heating circuits, side vents, shading screens, cooling, forced ventilation, etc.). Although not presented in this manuscript, models for the above mentioned components are included in the library. The modeling framework can thus be used for a wide range of greenhouse designs and climates.

In this work, the proposed models are used to investigate the influence of control strategies on the greenhouse energy consumption and crop yield through two case studies. The first case study focuses on intrinsic greenhouse components. For the particular case of the thermal screen, results indicate that just by delaying the deployment of the screen, heating consumption can be reduced by $3 \%$ with no loss of productivity. Moreover, outside temperature dependent radiation criterion can further reduce energy use with a small decrease on harvest. The second case study illustrates the impact of the control of the generation units on the operational costs. Results show that a mix electrical-heat-driven control that fosters electrical self-consumption can decrease operational costs by $17 \%$ with respect to a purely heat-driven control. It is also demonstrated that purely electrical-driven control strategies are not suitable for this kind of systems since they do not cover a sufficient share of the heating demand.

In conclusion, the presented open-source modeling framework can be used for a wide range of possibilities that can contribute to the necessary energy transition. Apart from optimizing the control strategies to drive productivity while reducing energy use, it can also evaluate the potential use of renewable energy sources (e.g. solar, geothermal), the use of energy-related emissions (e.g. waste-heat or $\mathrm{CO}_{2}$ emissions) or even the impact in the power grid by using 
existing CHP units for ancillary services.

\section{Acknowledgements}

The authors would like to thank the Walloon Region of Belgium for funding this research in the context of the EcoSystemePass project (convention 1510610).

\section{Nomenclature}

\section{Physic constants}

$\gamma \quad$ Psychrometric constant

$\sigma \quad$ Stefan-Boltzmann constant

$g \quad$ Gravitational constant

$R \quad$ Molar gas constant

\section{Subscripts}

$\begin{array}{ll}\tau & \text { Transmitted } \\ \text { acc } & \text { Accumulated } \\ \text { air } & \text { Greenhouse main air zone } \\ \text { amb } & \text { Ambient air } \\ b & \text { Boundary } \\ \text { buf } & \text { Carbohydrate buffer } \\ \text { can } & \text { Canopy } \\ \text { Carnot } & \text { Carnot Cycle } \\ \text { cell } & \text { Cells of a discretization model }\end{array}$

$$
\begin{array}{r}
\mathrm{Pa} \mathrm{K}^{-1} \\
\mathrm{~W} \mathrm{~m}^{-2} \mathrm{~K}^{-4} \\
\mathrm{~m} \mathrm{~s}^{-2} \\
\mathrm{~J} \mathrm{~mol}^{-1} \mathrm{~K}^{-1}
\end{array}
$$




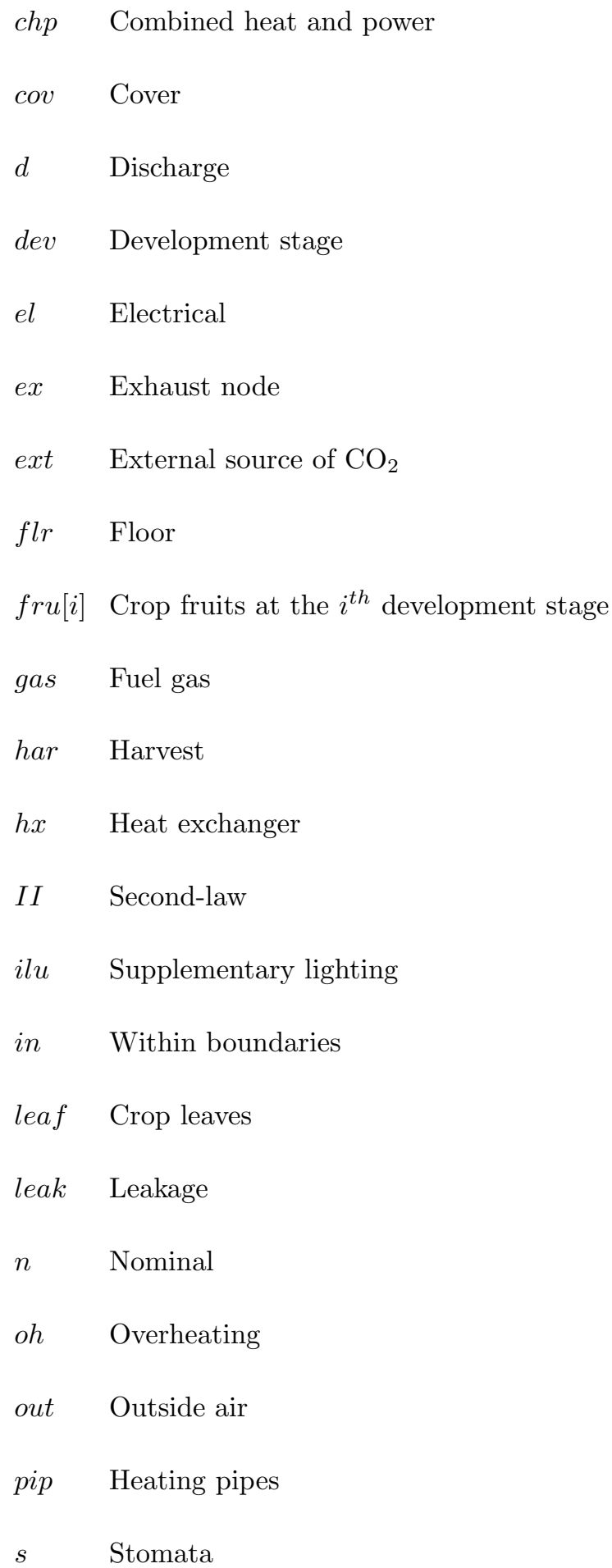




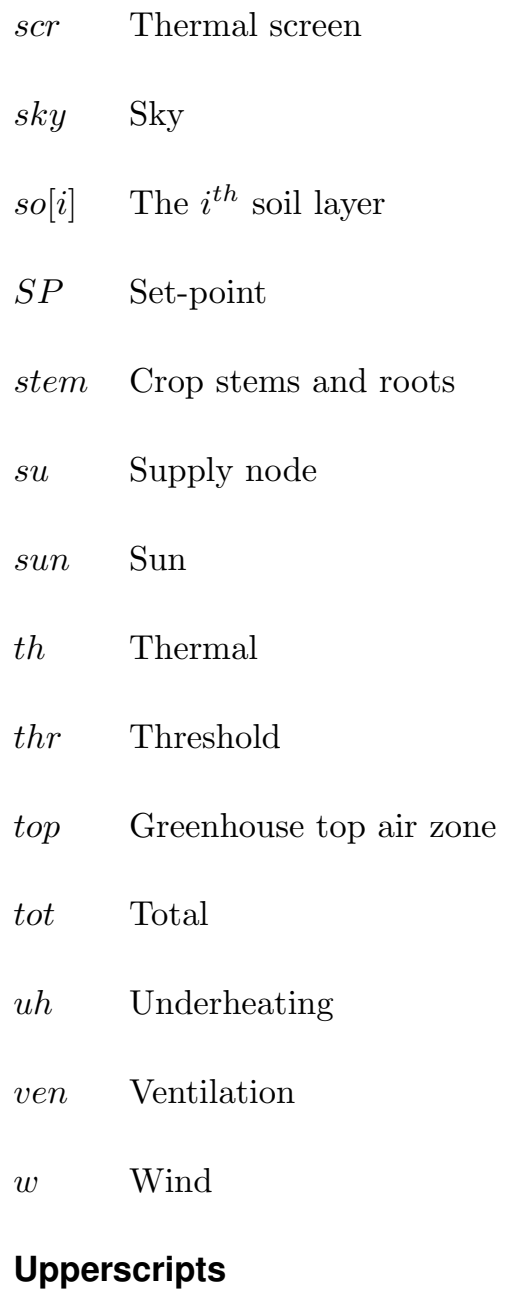




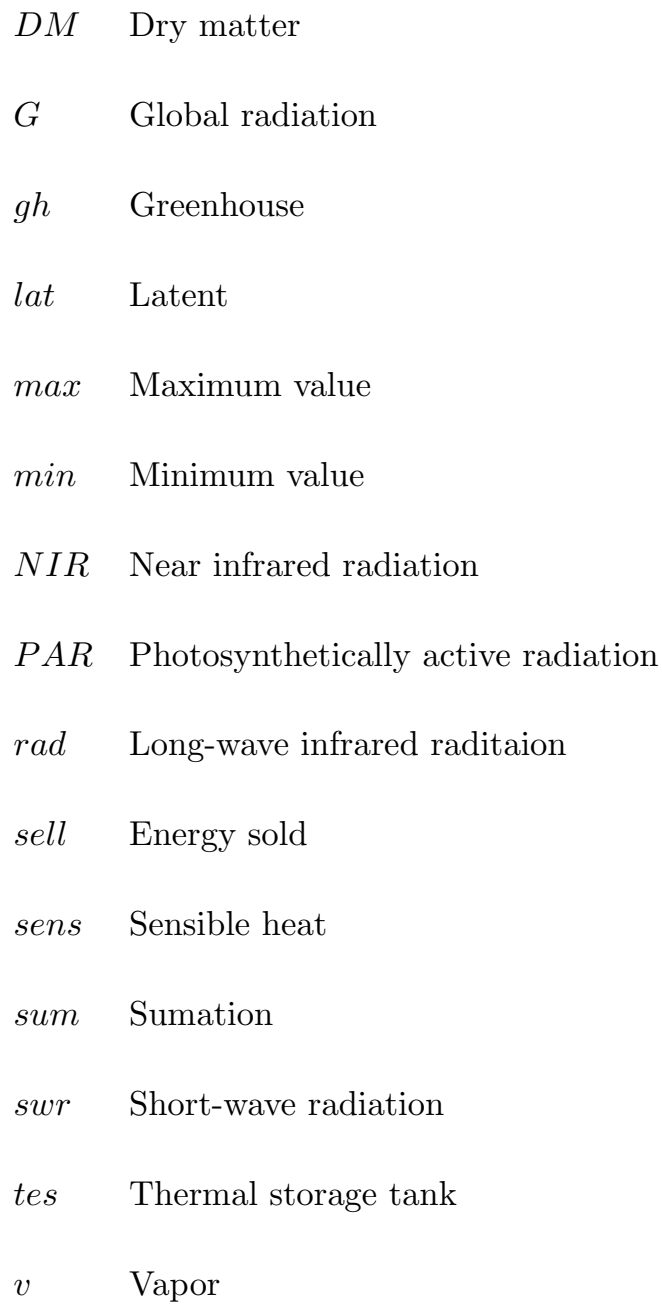

$\dot{M} \quad$ Mass flow rate $\quad \mathrm{kg} \mathrm{s}^{-1}, \mathrm{mg} \mathrm{s}^{-1}$ 
$\dot{m} \quad$ Mass flow rate averaged per square meter of greenhouse floor $\mathrm{kg} \mathrm{s}^{-1}$ $\mathrm{m}^{-2}, \mathrm{mg} \mathrm{s}^{-1} \mathrm{~m}^{-2}$

$\dot{n} \quad$ Number of fruits flow rate averaged per square meter of greenhouse floor

$$
\text { fruits } \mathrm{m}^{-2} \mathrm{~s}^{-1}
$$

$\dot{Q} \quad$ Heat flow $\quad$ W

$\dot{q} \quad$ Heat flow averaged per square meter of greenhouse floor $\quad \mathrm{W} \mathrm{m}^{-2}$

$\dot{v} \quad$ Air flow rate averaged per square meter of greenhouse floor $\quad \mathrm{m}^{3} \mathrm{~s}^{-1}$ $\mathrm{m}^{-2}$

$\dot{W} \quad$ Electrical power $\quad$ W

$\eta \quad$ Efficiency, ratio

$\gamma \quad$ Mass concentration $\quad \mathrm{mg} \mathrm{m}^{-3}$

$\begin{array}{ll}\lambda \quad \text { Thermal conductivity } & \mathrm{W} \mathrm{m} \mathrm{m}^{-1} \mathrm{~K}^{-1}\end{array}$

$\pi \quad$ Energy price $\quad \in \mathrm{MWh}^{-1}$

$\rho \quad$ Density, reflection coefficient $\quad \mathrm{kg} \mathrm{m}^{-3},-$

$\tau \quad$ Transmission coefficient, time constant $\quad-, \mathrm{s}$

$\varepsilon \quad$ FIR emission coefficient

$\varphi \quad$ Roof slope $\operatorname{deg}$

$\xi \quad$ Conversion factor

A Area $\quad \mathrm{m}^{2}$

$B$ Benefit $\in$

C Cost $\in$

$\begin{array}{lll}c_{p} & \text { Specific heat capacity } & \mathrm{J} \mathrm{kg}^{-1} \mathrm{~K}^{-1}\end{array}$

d Diameter $\quad \mathrm{m}$ 
E Integrated energy

$\mathrm{MWh}$

e Thickness

$\mathrm{m}$

$F \quad$ View factor

$h \quad$ Vertical dimension, enthalpy

$\mathrm{m}, \mathrm{J} \mathrm{kg}^{-1}$

I Solar irradiation

$\mathrm{W} \mathrm{m}^{-2}$

K Coefficient

$l \quad$ Length per square meter of greenhouse flooe

$\mathrm{m} \mathrm{m}^{-2}$

$L A I \quad$ Leaf area index

$\mathrm{m}^{2}\{$ leaf $\} \mathrm{m}^{-2}\{\mathrm{flr}\}$

M Molar mass

$\mathrm{kg} \mathrm{mol}{ }^{-1}$

$m \quad$ Mass averaged per square meter of greenhouse floor

$\mathrm{mg} \mathrm{m} \mathrm{m}^{-2}$

$N \quad$ Total number

$n \quad$ Number of fruits averaged per square meter of greenhouse floor fruits $\mathrm{m}^{-2}$

$P \quad$ Power input

$P^{v} \quad$ Vapor pressure of water

$\mathrm{Pa}$

$r \quad$ Resistance

$\mathrm{s} \mathrm{m}^{-1}$

RH Relative humidity

$S L A \quad$ Specific leaf area index

$\mathrm{m}^{2}\{$ leaf $\} \mathrm{mg}^{-1}$

T Temperature

$t \quad$ Time

$U \quad$ Heat exchange coefficient

$\mathrm{W} \mathrm{m}{ }^{-2} \mathrm{~K}^{-1}$

$u \quad$ Control variable 
$v \quad$ Speed $\quad \mathrm{m} \mathrm{s}^{-1}$

W Width of fully deployed screen $\quad \mathrm{m}$

\section{References}

[1] Eurostat (online data code: nrg_100a), last accessed 17/07/2018.

URL http://appsso.eurostat.ec.europa.eu/nui/show.do?dataset= nrg_100a\&lang=en

[2] CBS StatLine: Energieverbruik; land- en tuinbouw, last accessed $17 / 07 / 2018$.

URL http://statline.cbs.nl/StatWeb/selection/?DM=SLNL\&PA= 80382NED\&VW=T

[3] Climate Agreement, Tech. rep., Government of the Netherlands, The Hague (Jun. 2019).

URL https://www.government.nl/documents/reports/2019/06/28/ climate-agreement

[4] Warmtealliantie Zuid-Holland aan de slag met warmtenet, last accessed 13/10/2020 (Mar. 2017).

URL https://www.portofrotterdam.com/nl/ nieuws-en-persberichten/warmtealliantie-zuid-holland-aan-de-slag-met-warmtenet

[5] SOLHO: Solar thermal energy systems to power greenhouse farms, last accessed 13/10/2020.

URL https://www. solho.eu/

[6] A. Buck, S. Hers, M. Afman, H. Croezen, F. Rooijers, W. van der Veen, P. van der Wijk, T. Slot, The Future of Cogeneration and Heat Supply to Industry and Greenhouse Horticulture, Tech. Rep. 14.3D38.67, CE Delft, Delft (Oct. 2014). 
[7] J. P. Jiménez-Navarro, K. C. Kavvadias, S. Quoilin, A. Zucker, The joint effect of centralised cogeneration plants and thermal storage on the efficiency and cost of the power system, Energy 149 (2018) 535-549. doi: $10.1016 / \mathrm{j}$.energy.2018.02.025.

[8] CODE2, D5.1 - Final Cogeneration Roadmap Member State: The Netherlands, Tech. rep., Cogeneration Observatory and Dissemination Europe (Jul. 2014).

[9] CBS StatLine. Electricity; production and means of production, last accessed 16/10/2018 (2018).

URL https://opendata.cbs.nl/statline

[10] I. Lopez-Cruz, E. Fitz-Rodríguez, S. Raquel, A. Rojano-Aguilar, M. Kacira, Development and analysis of dynamical mathematical models of greenhouse climate: A review, European Journal of Horticultural Science 83 (2018) 269-279. doi:10.17660/eJHS.2018/83.5.1.

[11] D. Katzin, S. van Mourik, F. Kempkes, E. J. van Henten, GreenLight - An open source model for greenhouses with supplemental lighting: Evaluation of heat requirements under LED and HPS lamps, Biosystems Engineering 194 (2020) 61-81. doi:10.1016/j.biosystemseng.2020.03.010.

[12] F. Casella, J. G. van Putten, P. Colonna, Dynamic Simulation of a BiomassFired Steam Power Plant: A Comparison Between Causal and A-Causal Modular Modeling, ASME 2007 International Mechanical Engineering Congress and Exposition (2007) 205-216doi:10.1115/IMECE2007-41091.

[13] M. Wetter, W. Zuo, T. S. Nouidui, X. Pang, Modelica Buildings library, Journal of Building Performance Simulation 7 (4) (2014) 253-270. doi: $10.1080 / 19401493.2013 .765506$.

[14] F. Jorissen, G. Reynders, R. Baetens, D. Picard, D. Saelens, L. Helsen, Implementation and verification of the IDEAS building energy simulation 
library, Journal of Building Performance Simulation 11 (6) (2018) 669-688. doi:10.1080/19401493.2018.1428361.

[15] S. Quoilin, A. Desideri, J. Wronski, I. Bell, V. Lemort, ThermoCycle: A Modelica library for the simulation of thermodynamic systems, in: Proceedings of the 10th International Modelica Conference, 2014.

[16] F. Casella, A. Leva, Modelling of thermo-hydraulic power generation processes using Modelica, Mathematical and Computer Modelling of Dynamical Systems 12 (1) (2006) 19-33. doi:10.1080/13873950500071082.

[17] T. Resimont, Q. Altes-Buch, K. Sartor, P. Dewallef, Economic and environmental comparison of a centralized and a decentralized heating production for a district heating network implementation, Proceedings of the 10th International Conference on System Simulation in Buildings (Dec. 2018).

[18] Tencent×WUR Autonomous Greenhouses International Challenge 2019 , last accessed 13/10/2020 (2019).

URL http://www . autonomousgreenhouses .com

[19] G. Bot, Greenhouse climate : from physical processes to a dynamic model, PhD Thesis, Wageningen University (1983).

[20] H. De Zwart, Analyzing energy-saving options in greenhouse cultivation using a simulation model, PhD Thesis, Wageningen University (1996).

[21] I. Impron, S. Hemming, G. P. A. Bot, Simple greenhouse climate model as a design tool for greenhouses in tropical lowland, Biosystems Engineering 98 (1) (2007) 79-89. doi:10.1016/j.biosystemseng.2007.03.028.

[22] W. Luo, H. de Zwart, J. DaiI, X. Wang, C. Stanghellini, C. Bu, Simulation of Greenhouse Management in the Subtropics, Part I: Model Validation and Scenario Study for the Winter Season, Biosystems Engineering 90 (3) (2005) 307-318. doi:10.1016/j . biosystemseng. 2004.11.008. 
[23] R. J. C. van Ooteghem, Optimal Control Design for a Solar Greenhouse, IFAC Proceedings Volumes 43 (26) (2010) 304-309. doi:10.3182/ 20101206-3-JP-3009.00054.

[24] B. H. E. Vanthoor, C. Stanghellini, E. J. van Henten, P. H. B. de Visser, A methodology for model-based greenhouse design: Part 1, a greenhouse climate model for a broad range of designs and climates, Biosystems Engineering 110 (4) (2011) 363-377. doi:10.1016/j.biosystemseng.2011. 06.001

[25] C. Stanghellini, Transpiration of greenhouse crops : an aid to climate management, PhD Thesis, Wageningen University (1987).

[26] L. Balemans, Assessment of criteria for energetic effectiveness of greenhouse screens, PhD Thesis, Agricultural University, Ghent (1989).

[27] A. A. F. Miguel, Transport phenomena through porous screens and openings : from theory to greenhouse practice, $\mathrm{PhD}$ Thesis, Wageningen University (Jan. 1998).

[28] T. Boulard, A. Baille, A simple greenhouse climate control model incorporating effects of ventilation and evaporative cooling, Agricultural and Forest Meteorology 65 (3) (1993) 145-157. doi:10.1016/0168-1923(93) 90001-X.

[29] K. L. Coulson, Solar and Terrestrial Radiation, Elsevier, 1975. doi:10. 1016/B978-0-12-192950-3.X5001-3.

[30] J. Ross, Radiative transfer in plant communities, in: Vegetation and Atmosphere (Ed. J. L. Monteith), Academic Press, London, UK, 1975, pp. $13-55$.

[31] L. Urban, I. Urban, La production sous serre: La gestion du climat, 2nd Edition, Vol. 1, Lavoisier, 2010. 
[32] E. Dayan, H. van Keulen, J. W. Jones, I. Zipori, D. Shmuel, H. Challa, Development, calibration and validation of a greenhouse tomato growth model: I. Description of the model, Agricultural Systems 43 (2) (1993) 145-163. doi:10.1016/0308-521X (93) 90024-V.

[33] E. Heuvelink, Tomato growth and yield : quantitative analysis and synthesis, PhD Thesis, Wageningen University (1996).

[34] R. Linker, I. Seginer, F. Buwalda, Description and calibration of a dynamic model for lettuce grown in a nitrate-limiting environment, Mathematical and Computer Modelling 40 (9) (2004) 1009-1024. doi:10.1016/j.mcm. 2004.12.001.

[35] L. F. M. Marcelis, E. Heuvelink, J. Goudriaan, Modelling biomass production and yield of horticultural crops: a review, Scientia Horticulturae 74 (1) (1998) 83-111. doi:10.1016/S0304-4238(98)00083-1.

[36] I. Seginer, C. Gary, M. Tchamitchian, Optimal temperature regimes for a greenhouse crop with a carbohydrate pool: A modelling study, Scientia Horticulturae 60 (1) (1994) 55-80. doi:10.1016/0304-4238(94)90062-0.

[37] B. H. E. Vanthoor, P. H. B. de Visser, C. Stanghellini, E. J. van Henten, A methodology for model-based greenhouse design: Part 2, description and validation of a tomato yield model, Biosystems Engineering 110 (4) (2011) 378-395. doi:10.1016/j.biosystemseng.2011.08.005.

[38] P. A. Leffelaar, T. J. Ferrari, Some elements of dynamic simulation., in: Simulation and systems management in crop protection, Pudoc, Wageningen, 1989, pp. 19-45.

[39] S. Nilsen, K. Hovland, C. Dons, S. P. Sletten, Effect of CO2 enrichment on photosynthesis, growth and yield of tomato, Scientia Horticulturae 20 (1) (1983) 1-14. doi:10.1016/0304-4238(83)90106-1. 
[40] A. Elings, H. F. d. Zwart, J. Janse, L. F. M. Marcelis, F. Buwalda, Multipleday temperature settings on the basis of the assimilate balance: a simulation study, Acta Horticulturae (2006).

[41] J. M. Aaslyng, J. B. Lund, N. Ehler, E. Rosenqvist, IntelliGrow: a greenhouse component-based climate control system, Environmental Modelling \& Software 18 (7) (2003) 657-666. doi:10.1016/S1364-8152(03) 00052-5.

[42] J. Dieleman, L. Marcelis, A. Elings, T. Dueck, E. Meinen, Energy Saving in Greenhouses: Optimal Use of Climate Conditions and Crop Management, Acta Horticulturae (718) (2006) 203-210. doi:10.17660/ActaHortic. 2006.718 .22

[43] J. Dieleman, E. Meinen, L. Marcelis, Z. , E. Van Henten, Optimisation of $\mathrm{CO} 2$ and Temperature in Terms of Crop Growth and Energy Use, Acta Horticulturae 691 (Oct. 2005). doi:10.17660/ActaHortic.2005.691.16.

[44] R. I. Grange, D. W. Hand, A review of the effects of atmospheric humidity on the growth of horticultural crops, Journal of Horticultural Science 62 (2) (1987) 125-134. doi:10.1080/14620316.1987.11515760.

[45] B. J. Bailey, Control strategies to enhance the performance of greenhouse thermal screens, Journal of Agricultural Engineering Research 40 (3) (1988) 187-198. doi:10.1016/0021-8634(88)90206-5.

[46] A. Grisey, E. Brajeul, Serres chauffées: réduire ses dépenses énergétiques, 1st Edition, Editions Centre technique interprofessionnel des fruits et légumes (CTIFL), 2007.

[47] F. Casella, Simulation of Large-Scale Models in Modelica: State of the Art and Future Perspectives, 2015, pp. 459-468. doi:10.3384/ecp15118459.

[48] J. Dieleman, F. Kempkes, Energy screens in tomato: determining the optimal opening strategy, Acta Horticulturae (718) (2006) 599-606. doi: 10.17660/ActaHortic.2006.718.70. 
[49] GE Power | General Electric, last accessed 13/10/2020.

URL https://www.ge.com/power

[50] S. Quoilin, K. Kavvadias, A. Mercier, I. Pappone, A. Zucker, Quantifying self-consumption linked to solar home battery systems: Statistical analysis and economic assessment, Applied Energy 182 (2016) 58-67. doi:10.1016/ j.apenergy.2016.08.077.

[51] S. Pfenninger, J. DeCarolis, L. Hirth, S. Quoilin, I. Staffell, The importance of open data and software: Is energy research lagging behind?, Energy Policy 101 (2017) 211-215. doi:10.1016/j.enpol.2016.11.046. 